\title{
Doc/8R/40958-1
}

\section{Continuous Fiber Ceramic Composites}

\section{Phase II - Final Report}

October 31, 1997

Submitted to: U.S. Department of Energy

DOE Chicago Field Office

9800 South Cass Avenue

Argonne, Illinois 60439-4899

Cooperative Agreement: DE-FC02-92CE40998

Submitted by: Atlantic Research Corporation 5945 Wellington Road

Gainesville, Virginia 22965 


\section{DISCLAIMER}

This report was prepared as an account of work sponsored by an agency of the United States Govermment. Neither the United States Governmeat sor any agency thereof, nor eny of their employees, makes any warranty, express or implied, or assumes any legal liability or responsibility for the eccuracy, completeness, or usefulaess of any information, apparatus, product, or process disclosed, or represents that its use would not infringe privatefy owned rights. Refereace berein to any specific commercial product, process, or service by trade name, trademart, manufacturer, or otherwise does not necessarily constitute or imply its endorsement, recommendation, or favoriag by the United States Government or any agency thereof. The views and opinions of authors expréssed herein do not necessarily state or reflect those of the Uaited States Government or any agency thereof. 


\section{DISCLAIMER}

Portions of this document may be illegible in electronic image products. Images are produced from the best available original document. 


\section{Table of Contents}

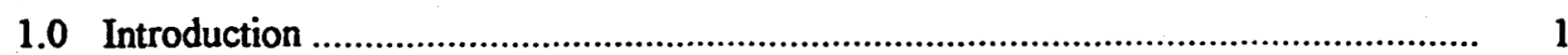

2.0 Technical Progress for Process Engineering and Component Fabrication \& Testing..... 3

2.1 Process Engineering ............................................................................................ 3

2.1.2 Nonoxidizing Interface .......................................................................... 3

2.1.2 Cold Tooling ........................................................................................ 6

2.1.3 C/SiC Composite Optimization .............................................................. 8

2.2 Component Fabrication \& Testing …........................................................... 10

2.2.1 Diesel Piston Rings ........................................................................ 10

- Component Design ............................................................................ 11

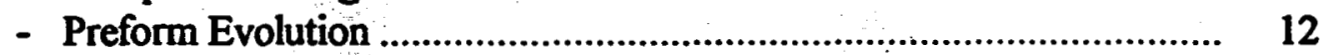

- Tooling Options .......................................................................... 13

2.2.2 Hot Gas Fans ................................................................................ 14

- Component Design ........................................................................... 14

- Fabric Deformation Experiments ........................................................ · 16

- Cold Tool Design and Fabrication ..................................................... 16

- Preform Evolution .......................................................................... 17

- Representative Parts ......................................................................... 19

- Machining and Dimensional Conformance ......................................... 20

- Proposed Simulation Tests ................................................................ 21

2.2.3 Hot Gas Filters .......................................................................... 23

- Component Design ............................................................................... 24

- Tooling Options .............................................................................. 25

- Preform Evolution ................................................................................ 26

- Representative Parts ....................................................................... 28

- Simulation Testing ............................................................................... 29

- Proposed End-User Service Tests ....................................................... $\quad 34$

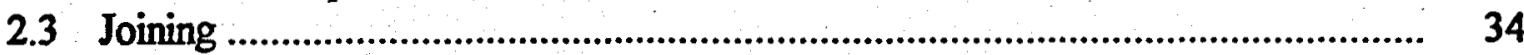

2.3.1 Composite to Composite ....................................................................... 35

2.3.2 Composite to Metal ...................................................................... 37

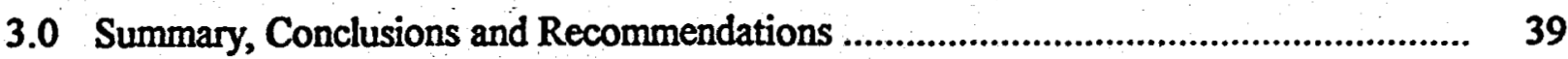

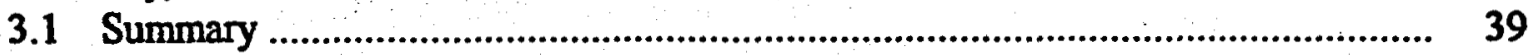

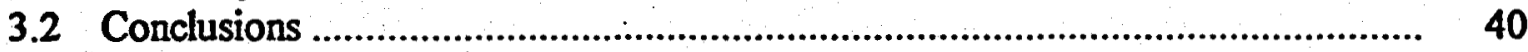

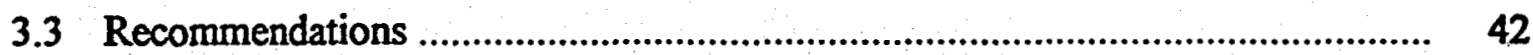




\subsection{Introduction}

This report documents Atlantic Research Corporation's (ARC) Phase II effort on the Department of Energy's (DOE) Continuous Fiber Ceramic Composite (CFCC) program. This project is supported by the DOE cooperative agreement DE-FC02-92CE40998. Such DOE support does not constitute an endorsement of the views expressed in this report. ARC's CFCC. Phase II effort began during October 1993 and was suspended in March of 1997 when, for business considerations, ARC closed the Amercom operation. This report covers progress from Phase II program inception through Amercom closure.

ARC's Phase II effort built upon the results of the Phase I Applications Assessment and Process Engineering developments to produce CFCC test components for end-user evaluation. Initially, the Phase II effort planned to develop and produce three CFCC components:

CFCC compression rings for stationary diesel engines,

CFCC hot gas fans for industrial furnace applications and

CFCC hot gas filters for current and advanced coal fired power cycles.

As the program progressed, the development effort for the diesel engine piston rings was suspended. This decision was based on technical issues, cost factors and reduced program funding; the status of CFCC diesel engine piston ring development will be discussed in detail in section 2.2.1.

ARC's Phase II effort planned for simulation testing and end-user service tests for each CFCC component. Unfortunately, the development of each selected component progressed at a different rate and only the hot gas filters progressed to simulation testing at the time of Amercom closure; none of the components achieved end-user service testing. The status of hot gas filter and hot gas fan testing will be discussed further in their respective report sections, 2.2.2 and 2.2.3.

Although the focus of the Phase II effort was on the fabrication and testing of CFCC components, certain Phase I Process Engineering tasks were continued into this phase to support the program goals. In addition to the original engineering tasks, a deficiency in the $\mathrm{C} / \mathrm{SiC}$ densification process led to the introduction of a $\mathrm{C} / \mathrm{SiC}$ process optimization task within Phase II. These tasks included:

Development of a nonoxidizing interface (NOI), development of cold tooling techniques and the optimization of $\mathrm{C} / \mathrm{SiC}$ CFCCs. 
The development of a nonoxidizing interface presented many challenges and consequently, progress was slow during the early effort. Fruition of this work was just emerging when the Amercom operation shutdown. By program's end, a functional interface had been developed that showed stability after precrack and oxidation. The as-fabricated stress/strain response of the NOI composite was somewhat less favorable than that of Amercom's carbon interfaced material. Optimization of NOI layer thicknesses should result in conventional stress/strain behavior of the NOI composites. Optimization of the as-fabricated composite was secondary to the optimization of retrained stress/strain response following precracking and oxidation. The Phase II progress and technical summary can be found in section 2.1.1.

The high cost of CFCC components precludes prototype manufacturing and component evaluation for many potential applications. Those organizations that did invest in CFCC development, and tested prototype components that met their requirements, were often discouraged by high production cost projections. Within the CFCC industry perhaps one to two hundred component development programs began over the last twelve years. Of these, only a handful ever reached any true level of production. The high cost of production stems from a number of individual cost elements, two of which being: inefficient tooling techniques and size limitations of a "production batch." ARC's Cold Tooling development effort was aimed at reducing the tooling costs with a coincidental enlargement of the "production batch" size. ARC's approach combined existing trapped rubber tooling concepts with CFCC compatible rigidizing compounds. During this program phase, Cold Tooling technology had produced full-scale hot gas fans with virtually no tooling in the CVD reactor. In section 2.1.2, ARC's progress in Cold Tooling Development will be discussed.

As an interim addition to the Phase II Program Plan, a Process Engineering Development task was created to optimize the $\mathrm{C} / \mathrm{SiC}$ densification process. This task became necessary when the mechanical performance of the $\mathrm{C} / \mathrm{SiC}$ (T-900 fiber) material system fell short of property predictions; the shortfall was significant and improvement was essential if the component was to succeed. This effort focused on increasing the material system's microcrack yield strength, ultimate tensile strength and strain at failure through processing variations. A discussion of the approach and results of this development effort can be found in section 2.1.3. 


\title{
2.1 Process Engineering
}

Process engineering focuses on the development work necessary to convert laboratory processes to ones suitable for the manufacture of representative components exhibiting the required properties and economics. For Amercom's Phase II effort these tasks included:

\author{
Continued development of a nonoxidizing interface, \\ continued development of cold tooling techniques and \\ a new task to optimize the material properties of C/SiC CFCCs.
}

\subsubsection{Nonoxidizing Interface}

The objective of this effort was to develop a thermally stable interface for the baseline CFCC material system, Nicalon/SiC. This interface must not only be thermally stable in inert environments, but also in oxidizing and reducing environments. Of these conditions, the most challenging is thermal stability in an oxidizing environment. For this reason the term "Nonoxidizing Interface" was applied to this development effort.

Amercom carried out investigation of NOIs prior to the CFCC Program. Initially, the approach was to apply numerous thin layers of a non-volatile material. This approach was referred to as "onion-skin." The theory was to provide as many crack deflecting paths as possible with a material that was not consumed by oxidation. Silicon carbide was selected as the non-volatile material. This was a natural choice since the technology to apply very thin layers was already known and, if successful, the interface application could be incorporated into the densification process without interruption. A very thin "flash" of pyrolytic carbon would be the first deposited surface on the Nicalon fiber to protect the fiber from chlorosilane attack. All attempts, including Auger, to measure the thickness of this "fllash" failed. Therefore, we assumed that layer thickness was on the angstrom level. Since the layer could not be measured, but its presence verified by fiber protection, this application of PyC was referred to as a "surface treatment" of the fiber. The layer was so thin that its presence, or absence should have no effect on the mechanical performance of the interface. In other words, if the thin carbon layer was removed by oxidation, the performance of the composite system would not be adversely effected. The pre-CFCC program panels produced using the onion-skin interface approach showed promise and was the starting point for NOI development under the CFCC effort.

Within the CFCC Program, several Nicalon/SiC panels were produced using the onionskin approach and tested both before and after oxidation exposure. These panels contained between six and eight $\mathrm{SiC}$ interface layers with a total interface thickness of 
approximately $1.0 \mu$; all layers were approximately equal in thickness. As-fabricated mechanical properties were comparable to the baseline carbon interfaced Nicalon/SiC properties, UTS between 30 and $35 \mathrm{ksi}$, microcrack yield between 10 and $15 \mathrm{ksi}$ with strain at failure between 0.6 and $0.8 \%$. Oxidation exposure was underway when a procedural review shed light on a shortcoming of the exposure test; the oxidation exposure was too conservative and did not subject the test article to active oxidation. The oxidation exposure test was revised and the revised test was adopted as the standard test for all further CFCC oxidation testing.

The revised oxidation exposure test mandated pre-stressed test coupons. Any material supplied for oxidation exposure would be tensile loaded to its microcrack yield prior to oxidation exposure and then each test coupon would be placed in an air furnace at $1000^{\circ} \mathrm{C}$ for at minimum of 75 hours. The intent was to fully microcrack the SiC matrix and open oxidation paths into the interface regions. We recognized that this was an extremely aggressive test but the end-user service environments are equally severe and any CFCC component supplied to an end-user should be able to withstand this type of exposure. All of Amercom's phase II oxidation exposure tests followed this procedure.

When this more rigorous oxidation test was applied to the onion-skin interface approach, the post-exposure coupons showed brittle fracture at very low tensile loads; the interface had failed. A fair amount of time was invested in understanding this failure with significant contributions from our University of Virginia partner. The final conclusion, supported by microstructural analysis, was that separate $\mathrm{SiC}$ interface layers grew together and bonded by the formation oxides (primarily $\mathrm{SiO}_{2}$ ) during oxidation exposure. Once the individual layers became bonded, they acted as a single monolithic layer and ceased to function as a crack deflecting interface. The onion-skin approach was abandoned.

Since organic interfaces are consumed by oxidation and non-oxide ceramics grow oxide layers when oxidized, the next logical step is to investigate oxides as potential CFCC interfaces. These materials are non-volatile and completely stable in oxidizing environments. Amercom investigated a number of oxide chemistries including: yttria, tantalum oxide, niobium oxide and alumina. Each of these compounds were applied to conditioned Nicalon (PyC flash coating for fiber protection) preforms and then densified with $\mathrm{SiC}$. Each of these materials were deposited as a two layer interface with a thin (angstrom level) growth interruption layer between the two oxide interface layers. Both interface layers were always the same chemistry.

Densification and testing of the oxide based interfaces resulted in the selection of Alumina for continued interface development. This selection was based on superior composite performance with the alumina interface over the other oxide interface chemistries. The oxide interface selection effort was brief and the fact that the other chemistries did not perform as well does not imply that those interfaces did not work. Simply, the Alumina 
worked the best in our evaluation. Given the financial and schedule constraints of the NOI work, we focused on developing the alumina interface.

Through process refinements to improve the interface morphology and deposition uniformity, the as-fabricated composite strength and strain at failure began to improve. Concurrent studies to investigate the effect of interface layer thicknesses also began. By program's end we had determined that a NOI composed of a PyC flash layer for fiber protection, $0.4 \mu$ layer of $\mathrm{Al}_{2} \mathrm{O}_{3}$, a growth interruption layer ( $<0.1 \mu \mathrm{PyC}$ ), and another $0.4 \mu$ layer of $\mathrm{Al}_{2} \mathrm{O}_{3}$ was the best functioning interface. The $\mathrm{SiC}$ matrix could be grown directly on top of the second $\mathrm{Al}_{2} \mathrm{O}_{3}$ layer. With this formula, several experimental panels were fabricated. For every batch of NOI experimental panels, a standard PyC interfaced panel was coprocessed. By the end of Amercom's experimental series, the following results had been reported:

\begin{tabular}{|l|c|l|c|l|r|r|}
\cline { 2 - 7 } \multicolumn{1}{c|}{} & \multicolumn{2}{c|}{ As-Fabricated } & \multicolumn{2}{c|}{ Post Exposure* $^{*}$} & \multicolumn{2}{c|}{ Property Retention } \\
\cline { 2 - 7 } \multicolumn{1}{c|}{} & UTS & Strain $_{\text {MAX }}$ & UTS & Strain $_{\text {MAX }}$ & UTS & Strain $_{\text {MAx }}$ \\
\hline PyC & $168 \mathrm{MPa}$ & $0.55 \%$ & $14 \mathrm{MPa}$ & $0.008 \%$ & $8.3 \%$ & $1.5 \%$ \\
\hline NOI & $163 \mathrm{MPa}$ & $0.25 \%$ & $106 \mathrm{MPa}$ & $0.090 \%$ & $65 \%$ & $36 \%$ \\
\hline
\end{tabular}

* Post exposure specimens were pre-stressed to microcrack yield and then placed in an air furnace at $1050^{\circ} \mathrm{C}$ for 100 hours.

All reported values are the average of four tensile tests.

A typical PyC interfaced Nicalon/SiC composite has an UTS of approximately $230 \mathrm{MPa}$ with a strain at failure of between $0.6 \%$ and $0.8 \%$. The PyC control specimen for this test series fell short of typical composite properties. However, since all panels were coprocessed, any densification process anomaly would have had a comparable effect on the NOI panels. For this reason we concluded that in the as-processed condition, the NOI interface was roughly equivalent in performance to the PyC interface.

The most significant data is presented in the "Property Retention" column. After prestress and oxidation exposure the NOI specimens retained much more load carrying capability than the PyC specimens. It should be noted that the PyC specimens performed typically after pre-stress and oxidation exposure; loss of virtually all strength and strain capability was seen repeatedly in all PyC control panels throughout this program. The fact that a CFCC retained $65 \%$ of its UTS and $36 \%$ of its strain capability after oxidation exposure is a remarkable achievement.

The data indicates that an oxidation resistant interface has been developed. Continued effort should be directed at improving the as-fabricated mechanical performance of the 
oxide based interface and further improvement of mechanical property retention following pre-stress and oxidation exposure. The path to a NOI has been illuminated, others must build from these developments and continue down this path to develop a true NOI.

\subsubsection{Cold Tooling}

The objective of this effort was to reduce the cost of manufacturing CFCC components, thereby reducing the price of components to the end-user and making the product "more attractive." Tooling costs, for all but the simplest flat plate, can often be the largest single cost in the manufacturing of CFCC components. Within this effort Amercom sought to eliminate the single use hot tooling in favor of reusable cold tooling. Typically, hot tools are machined from graphite and accompany the ceramic preform through, at least the early stages of, the densification process. These tools debulk the ceramic fiber preforms while maintaining geometric control of the preform/composite during densification. By comparison, cold tools are machined from conventional metals (low carbon steel, aluminum, etc.) and are not subjected to chemical vapor deposition (CVD) processing. For this reason, they are reusable indefinitely. Debulking and preform shaping is accomplished outside of the reactor, so only near-net-shape preforms are included within the CVD batch process. Since no tooling accompanies cold tooled preforms during densification, there is more reactor volume available for component preforms. This can represent tremendous savings in the cost of CFCC manufacturing.

Amercom continued the cold tooling development effort that began in the CFCC Phase I program. In Phase I, preceramic polymers were screened for their suitability as cold tooling compounds. Phase II sought to combine trapped rubber tooling techniques with appropriate preceramic polymer binders. Trapped rubber tooling technology has been used for many years in the organic composite industry. Amercom learned of this technique on previous programs and quickly began the transition of this process into one suitable for ceramic matrix composites. As the CFCC Program evolved, it became clear that cold tooling via trapped rubber was an essential technology toward the program goal of commercially viable CFCC components.

Conceptually; a trapped rubber tool is a multi-segment metal tool with a fully enclosed internal cavity. The internal cavity conforms to the desired component geometry with an expansion of the cavity over one surface of the component geometry to accommodate the rubber. A preform is loaded into the tool against one surface of the metallic tool. Rubber tooling components are added over the second preform surface and fill the entire tool cavity. The tool is assembled and heated to design temperature, typically $<200^{\circ} \mathrm{C}$. As the tool is heated, the rubber expands and exerts a uniform pressure on the preform, debulking . the preform. With the presence of certain organic or preceramic agents, the preform can be bound into the geometry imparted by the tool. In this way, the preform is simultaneously debulked and formed by the cold tooling process. A rigid preform is 
removed from the trapped rubber tool. This preform is now ready for densification without the aid of hot tooling.

The early work with this concept employed phenolic resins to maintain geometric control over the preforms. By proper control of resin viscosity, the cold tooling compound would also form a suitable carbon interface. This was extremely advantageous since the question of "Which comes first, the interface or the cold tooling compound?" never required an answer. However, with the CVD approach to a NOI the answer to this question becomes very important.

Although formal experiments were never carried out, Amercom believed that the interface should be placed directly onto the fiber and then the interfaced preform could be cold tooled into the appropriate geometry. This selection was based on Amercom's understanding of crack propagation mechanics and the perception that the interface functions best when it is immediately adjacent to the fiber. While all this looks good on paper, this approach is not without risk. In the late eighties, Amercom performed a development effort on some thick cross section Nicalon/SiC composite components. Initial infiltration trials resulted in an unacceptable interface thickness gradation through the preform thickness. Trials were performed with hot tooling to debulk the preform to the target $40 \%$ fiber volume fraction. A decision was made to deposit the interface without the presence of hot tools and then debulk the interfaced preform for $\mathrm{SiC}$ densification. The interface was applied and measurement confirmed uniform application. The preforms were compressed to form a 40v/o panel and densified. When the panels were complete, a tensile specimen was cut from each test panel and tensile tested. The results of the tensile tests were poor and indicated a process problem, most likely failure of the interface. Scanning electron microscopy showed apparent degradation of the Nicalon and interface spalls completely encased in $\mathrm{SiC}$ matrix material. It was obvious that debulking the interfaced preform had compromised the interface. Without an interface, the unprotected fibers were chemically attacked by the SiC precursor. The "flexing" of an interface to accommodate debulking and component shaping has yet to be demonstrated.

Amercom's Phase II effort focused on the direct application of cold tooling for each of the three selected CFCC components. For the hot gas fan, cold tooling was essential; the use of disposable hot tools for multiple hot gas fan prototype components would have been cost prohibitive. With the hot gas filters and the piston rings, hot tooling costs were acceptable during the component development effort, however, cold tooling would be required in both cases to meet the production cost targets for these components.

Amercom never reached the point in the cold tooling work where the preceramic polymers, investigated in Phase I, were applied to CFCC preforms. All hot gas fan segments that were produced during this program phase used a phenolic resin as the cold tooling compound. The use of phenolic resin was appropriate because the NOI was still under development and unavailable for CFCC prototypes. Until the NOI was completed, 
all CFCC prototype components would contain a pyrolytic carbon interface. With the carbon interface, the presence of an additional resin derived carbon binder would have no appreciable effect on prototype performance.

The next step in cold tooling development must be to marry a NOI with preceramic polymer binders in a cold tooling process. The combination of a thermally stable interface with the process economies made possible by cold tooling will deliver commercially viable CFCC components. Additional markets will open up when the first CFCC component is commercially accepted.

\subsubsection{C/SiC Composite Optimization}

This task was added to the program plan as an interim process development task. The inclusion of this task became essential after preliminary results from piston ring test coupons indicated a strength deficiency with the T-900/SiC material system.

The objective of this task was to further develop and optimize the densification process for Toray's T-900 carbon fiber. The existing process produced mechanically sound composites, however, they did not fully achieve their mechanical property predictions. A parametric study was devised to evaluate process variables and increase the mechanical performance of this material system. The intended component was to be reinforced with a 3-D braid, however the cost of this preform architecture precluded its use during optimization effort. The bulk of the work would be carried out on $\mathrm{T}-900 / \mathrm{SiC}$ flat plate with an $8 \mathrm{HS}$ weave construction. Once the process conditions were established, a small quantity of multi-layer $\left(0 \pm 60^{\circ}\right)$ triaxial braided tubing would be processed. This braided tube was similar in construction to the planned ring preform and would be used to verify that the newly developed process was suitable for this type of architecture.

The root of the deficiency seemed to be interface performance, so a four-experiment plan was developed to vary the PyC interface thickness. A minimum thickness of $0.2 \mu$ was established and tests would be performed at $+0.2 \mu$ intervals up to a total interface thickness of $0.8 \mu$. Specifically, T-900/SiC flat plates would be fabricated and tested with PyC interface thicknesses of: $0.2 \mu, 0.4 \mu, 0.6 \mu$ and $0.8 \mu$. The processing plan called for all plate preforms to be co-processed for a $0.2 \mu$ PyC interface coating. Then one plate preform would be removed and an identical CVD run would be performed, adding a $0.2 \mu$ thick PyC coating to the remaining three preforms. Once again, one plate preform would be removed (total PyC thickness $0.4 \mu$ ) and the process repeated until one of each of the desired interfaces had been produced. The result of this process plan was a layered PyC interface coating for all evaluation panels with an interface thickness greater than $0.2 \mu$. To eliminate layered interfaces as an experimental variable, a fifth plate preform received a single $\mathrm{PyC}$ layer of $0.6 \mu$. 
Naturally, the target interface thicknesses were only goals. The actual interface thickness measurements were used for data reduction. The following measurements were taken from the test articles; numbers in parenthesis are the number of layers used to create the total reported thickness.

\begin{tabular}{|l|l|l|l|l|l|}
\hline Target thickness: & $0.20 \mu$ & $0.40 \mu$ & $0.60 \mu$ & $0.80 \mu$ & $0.60 \mu$ \\
\hline Actual thickness: & $0.18 \mu(1)$ & $0.40 \mu(2)$ & $0.57 \mu(3)$ & $0.79 \mu(4)$ & $0.59 \mu(1)$ \\
\hline
\end{tabular}

All panels were densified with $\mathrm{SiC}$ as a single batch. Each densified composite plate was machined into ten dogbone specimens. All tensile tests were performed at room temperature. The results are shown below.

\begin{tabular}{|l|c|c||c|c|}
\hline Interface Thickness (layers) & UTS & S.D. & Strain & S.D. \\
\hline $0.18 \mu(1)$ & $162.6 \mathrm{MPa}$ & $12.7 \mathrm{MPa}$ & $0.24 \%$ & $0.028 \%$ \\
\hline $0.40 \mu(2)$ & $199.5 \mathrm{MPa}$ & $9.3 \mathrm{MPa}$ & $0.50 \%$ & $0.033 \%$ \\
\hline $0.57 \mu(3)$ & $262.6 \mathrm{MPa}$ & $15.6 \mathrm{MPa}$ & $0.55 \%$ & $0.047 \%$ \\
\hline $0.79 \mu(4)$ & $219.8 \mathrm{MPa}$ & $14.7 \mathrm{MPa}$ & $0.40 \%$ & $0.044 \%$ \\
\hline $0.59 \mu(1)$ & $228.1 \mathrm{MPa}$ & $13.4 \mathrm{MPa}$ & $0.54 \%$ & $0.045 \%$ \\
\hline
\end{tabular}

The peak strength and maximum elongation occurred in the panel with a total PyC interface thickness of $0.57 \mu$ (in three layers.) This was most interesting since the panel with a $0.59 \mu$ single layer achieved only $87 \%$ of the multi-layered panel's strength. Data scatter does not account for this, because the standard deviation for both tests in question was approximately $5.9 \%$ and the difference of $0.02 \mu$ interface coating thickness between these two panels was deemed insignificant. This indicated that a multi-layered interface had an affect on the mechanical performance of the composite and the affect was beneficial.

The best performing T-900/SiC composite contained three layers of PyC. The logical question was "Do we really need three layers, or will two layers work just as well?" To answer this question, at least five interface runs were required (six if you include a control panel to verify the $\mathrm{SiC}$ densification process) and then a full $\mathrm{SiC}$ densification process.

This was a very expensive and time consuming experimental series. A decision was made to process two triaxially braided tubes with two equal PyC layers to a total interface thickness of $0.57 \mu$. The tubular preforms were prepared for CVD processing. The target PyC thickness for the first run was about $0.28 \mu$. Run time was calculated from the flat panel data and the process performed. PyC thickness measurements average $0.35 \mu$. The absence of tooling and the braids more accessible interior pores had increased the 
efficiency of the interface deposition. The addition of a $0.22 \mu$ PyC layer would bring the total interface thickness to the target value of $0.57 \mu$, however, the two interface layers would not be of equal thickness. This appeared to be the best option given financial and schedule constrains. Run time for a $0.22 \mu$ PyC layer was calculated based on rate data from the first PyC run. Post run evaluation resulted in an average total interface thickness of $0.55 \mu$. These tubes were tested in hoop burst. Property predictions called for an ultimate tensile strength of $345 \mathrm{MPa}$ with $0.8 \%$ strain. Average UTS was $304 \mathrm{MPa}, 88 \%$ of theoretical, with a $0.6 \%$ average strain at failure. These properties were sufficient for the diesel piston ring application and no further $\mathrm{T}-900 / \mathrm{SiC}$ process development was performed.

\subsection{Component Fabrication \& Testing}

The objectives of this task were to:

demonstrate an ability to process component geometries representative of the selected applications and,

verify the component design through testing of components in simulated and enduser service environments.

Amercom's Phase II program plan called for a detailed component design and process plan for each of the selected representative components. In Amercom's case there were three selected components: diesel piston rings, hot gas fans and hot gas filters. In each case, the component design would address the fiber reinforcement selection, preform architecture selection, matrix selection, component thickness, finite element analysis and attachment. Following component design, preforming trials and/or process development experiments would be performed. An appropriate number of representative components would be decided upon and then produced. Finally, the representative components would be delivered to the appropriate team member for simulation testing and ultimately delivered to an end-user for environmental testing.

As the program evolved, each component progressed at a different rate through this fabrication and testing plan. The following sections address the development progression of each of the three selected components.

\subsubsection{Diesel Piston Rings}

Environmental Protection Agency (EPA) mandates require reduced diesel engine emissions beginning in 1997. Detroit Diesel Corporation, in compliance with EPA mandates, sought to reduce particle emissions on their stationary diesel engines by replacing the metallic compression ring with a CFCC ring. The main source of diesel exhaust particulate is the passage of lube oil into the combustion cycle of the engine and 
then out through the exhaust pipe. The primary lube oil flow path is behind the piston ring, through the piston's ring groove. The size of this passage increases as the compression ring wears against the piston's groove and cylinder walls. The term "blowby" is used to describe this emission source. The primary advantage of a CFCC ring is improved wear resistance which will reduce diesel engine blow-by.

The CFCC piston ring presented many challenges, not the least of which was the goal of a $\$ 10$ selling price. The extremely tight component tolerance, plus the fact that the ring had to be opened for piston installation and closed for block insertion further complicated the design and kept prototyping costs high. With these challenges in mind a FEA analysis was completed to determine the optimum preform architecture and component geometry. The FEA was based on the limited available data and $\mathrm{C} / \mathrm{SiC}$ property predictions. Concurrent with preform manufacture, tooling options were evaluated. With a target selling price of $\$ 10$, it was clear that cold tooling operations would be required for production. However, with the expected variability in prototype preforms, uncertainty in thermal expansion and the desire to have all preform fiber elements completely encased in the $\mathrm{SiC}$ matrix, it was decided to use hot tooling for initial ring development. Eventually, design complications with the hot tool and technical difficulties in preform manufacturing resulted in an overrun of those task's budgets. Prototype fabrication of the CFCC piston ring was suspended. A summary of these operations are reported below.

\section{Component Design}

Detroit Diesel Corporation provided the existing design for the corresponding metallic compression ring. The metal ring possessed a basic keystone cross section, with a barrel shaped contact surface at the cylinder wall. The tolerances on the barrel figure $\left( \pm 6 \times 10^{-6}\right.$ inches) and envelope dimensions on the keystone shape ( $\pm 2 \times 10^{-3}$ inches) were too tight for accurate near-net-shape preform placement techniques. The preform would have to be controlled within a smaller envelope. Excess matrix material would be added to the appropriate surfaces such that final machining could be controlled within the monolithic $\mathrm{SiC}$ overcoat.

T-900 carbon fiber was selected, in lieu of the program baseline fiber, as the reinforcement for the piston ring. This selection was made because the property of most interest in the ring application was wear resistance as opposed to high temperature stability. The selected carbon fiber could withstand the operating temperature of the diesel engine and was less expensive than Nicalon. Additionally, T-900 has a filament diameter of $4.5 \mu$ and is available in a $1 \mathrm{~K}$ tow (200 denier equivalent); Nicalon filament diameter is $15 \mu$ and is : available in a 900 denier tow. The finer tow bundles of T-900 were more suitable to the small preform unit cell size required by the piston ring geometry.

Prototype manufacturing was further simplified by the adoption of a simple, rectangular cross section for the prototypes. All selected manufacturing operations were adaptable to 
the final keystone cross section. However, in the interest of time and economy, rectangular rings would be tested during the Simulation Testing portion of the program.

With the geometric constrains of the ring established, Materials Sciences Corporation was directed to perform a FEA analysis. This analysis resulted in the selection of a 3-D braid with $0 \pm 60^{\circ}$ construction and a ring I.D. of $125 \mathrm{~mm}$. The radial thickness of the ring would be $5 \mathrm{~mm}$ (135mm O.D.) and the cylindrical height of the ring would match its metal counterpart. This design provides for minimal hoop stress during installation, over a $130 \mathrm{~mm}$ OD piston and into a $130 \mathrm{~mm}$ cylinder, $-87 \mathrm{MPa}$ and $+92 \mathrm{MPa}$ respectively. This design also provides for maximum transverse shear modules (to minimize ring twist) and maximum resistance to transverse shear-out at the groove.

\section{Preform Evolution}

The original plan was to order a large quantity (40') of ring preform material as a continuous run, cut into ten four foot lengths; this would allow production of approximately 90 piston rings. As braiding proceeded, the braider encountered difficulties achieving the target braid angle of $60^{\circ}$. Physical measurement of the preform resulted in an actual bias braid angle of $42^{\circ}$; significantly off the target braid angle. To compound the problem, an increasing number of fiber tows would break as attempts were made to increase the bias braid angle. An FEA analysis of a $0 \pm 42^{\circ}$ piston ring structure was performed and found to be far less than optimal. The preformer was asked to develop an ability to meet the original design requirements.

The second preform iteration resulted in a bias braid angle of between $\pm 55^{\circ}$ and $\pm 60^{\circ}$ with virtually no broken fiber tows and an as-braided fiber volume fiber fraction of approximately 0.40 . Approximately nine feet (six lengths of $18^{\prime \prime}$ each) of this material was delivered to Amercom. Some of this material was processed into bend bar specimens and some was used to evaluate the formability of the 3-D architecture. The strength results of the bend bar tests were below expectations and these low results precipitated the C/SiC Composite Optimization task (see section 2.1.3). Formability experiments revealed buckling problems with the 3-D braid architecture. Controlled deformation techniques with and without solvents to aid preform slippage were evaluated. None provided a uniformly distorted preform suitable for use as a piston ring preform.

For the third preform iteration, the preformer was asked to provide hoop segments instead of straight "bar" segments. Through braid development, and by preferential pulling of the preform during braiding, the preformer accomplished this task. Twelve hoop segments with an approximate radius of $65 \mathrm{~mm}$, approximate bias braid angles of $\pm 60^{\circ}$, minimal fiber breakage and an as-braided fiber volume fraction of 0.40 were delivered to Amercom. The mechanical drawing, supplied to the preformer, for braided hoop preforms is shown on the next page. 

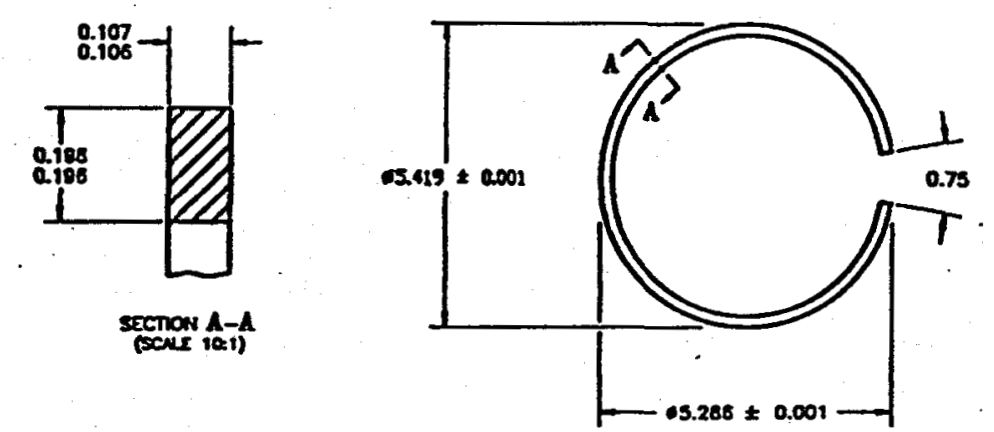

MATERINL: T-200 PREFORU PER AC100128, REV B.

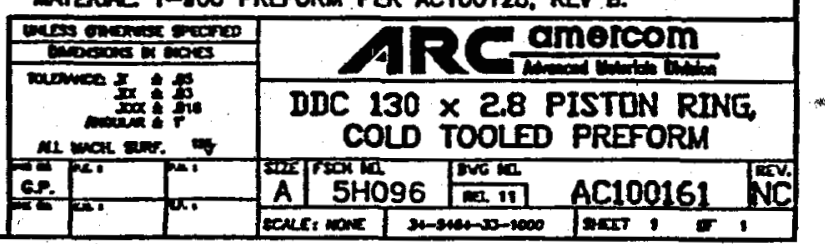

Amercom drawing AC100161, preform for DDC diesel piston ring.

The third iteration preforms were suitable for prototype manufacture of Detroit Diesel Corporation's CFCC piston ring. Unfortunately, the cost of prototype preform braiding was approximately $\$ 1,000$ each, with Amercom supplied fiber. Discussions with the preformer and production extrapolations into the tens of thousands per year resulted in projected production costs for 3-D braiding of $<\$ 100$ per article, still with Amercom supplied fiber. The projected cost of preforming was an order of magnitude greater than the target price of the CFCC ring.

\section{Tooling Options}

Throughout the component design and preform evolution tasks, tooling options were under consideration. It was clear that reusable tooling would be required to meet the target selling price; however, the design and manufacturing cost of a cold tool precluded its use at this stage of development. Since the final CFCC ring geometry and preform constraint volume were continually evolving, hot tooling was chosen as the method for prototype manufacture.

A family of hot tools were designed with variations for the number of prototype rings per experimental nu. Final dimensions for the hot tools depended solely on first article preform measurements (as-received versus debulked dimensions), and the number of rings that were to be formed by a single hot tool.

Concurrent development for cold tooling was also performed. A trapped rubber tooling consultant was retained to develop tooling concepts for both prototype and full-scale 
production tools. The small preform volume versus the relatively large component size, combined with the fact that the as-braided fiber volume fraction was very near the target fiber volume fraction of the composite, complicated conventional cold tooling approaches. An all metallic tooling concept, referred to as delta alpha, was devised. Amercom had used this type of tooling in the past for the manufacture of metal matrix composites, but never for ceramic matrix composites. These tools exploited differences in the thermal expansion of various tool elements to form and debulk the preform. In contrast to trapped rubber, delta alpha tool requires precise machining of all tooling elements; there is no compliant rubber to accommodate local preform variations. The concept appeared valid, however, a cold tool design for piston ring manufacture was never completed.

As a point of fact, no tooling for the piston ring was ever completed. This was due to a late design iteration received from Detroit Diesel Corporation. The new design for their simulation test apparatus required elliptical ring geometry. The cost to the Program for another FEA analysis of an elliptical ring, obvious increases in hot tool machining costs plus the fact that the third iteration preforms may not conform to the new geometric requirements led to a suspension of the CFCC ring development.

\subsubsection{Hot Gas Fans}

Surface Combustion of Maumee, Ohio was our OEM for CFCC hot gas fans development. They identified their Batch Integral Quench (BIQ) furnace as the product to introduce a CFCC fan option. The existing fan for the BIQ furnace was an Inconel alloy casting, webbed paddle wheel design with a weight in excess of one-hundred pounds. The deficiency with the current material was paddle blade creep which eventually created an out-of-balance condition and necessitated fan replacement. A CFCC design was conceived with a twisted plate approach. Each fan would be constructed of three fan blade segments with a $60^{\circ}$ rotation between stacked segments. Each twisted plate segment would be formed by capturing the plate center (hub region) and twisting the plate ends to form two opposing perpendicular plates (paddle blades). Although the basic geometry was simple, "twisting" a ceramic preform was not trivial. A number of forming experiments were carried out before fan blade segments could be made repeatedly.

\section{Component Design}

With the basic fan blade construction defined, Materials Sciences Corporation was directed to study hub length/twist length/paddle length trade-offs with corresponding finite element analysis. The conditions for the FEA included a blade thickness of 0.080", 1,200 $\mathrm{rpm}$ at $2,000^{\circ} \mathrm{F}$ and start-up acceleration of $600 \mathrm{rpm} / \mathrm{sec}$. Fan blade material was assumed to be a 2-D layup of Nicalon (fabric construction TBD) at 40v/o in a SiC matrix with final composite density at $90 \%$ of theoretical. Six design options were offered by MSC. For each option, the in-plane rotational stress, in-plane shear stress and out of plane shear stress were all on the order of $1 \mathrm{Ksi}$, well below microcrack yield stress. Surface 
Combustion wanted the longest paddle length possible to move the most hot gas.

Amercom wanted the longest twist length possible to ease manufacturing complications. The design approach mandated a hub radius of 2.75 " to accommodate the stack rotation. Given these constraints, a compromise was reached. The CFCC fan would have a hub radius of 2.75", a twist length of $4.13^{\prime \prime}$ and a paddle length of 5.12". The mechanical drawing of a CFCC hot gas fan blade segment is shown below.

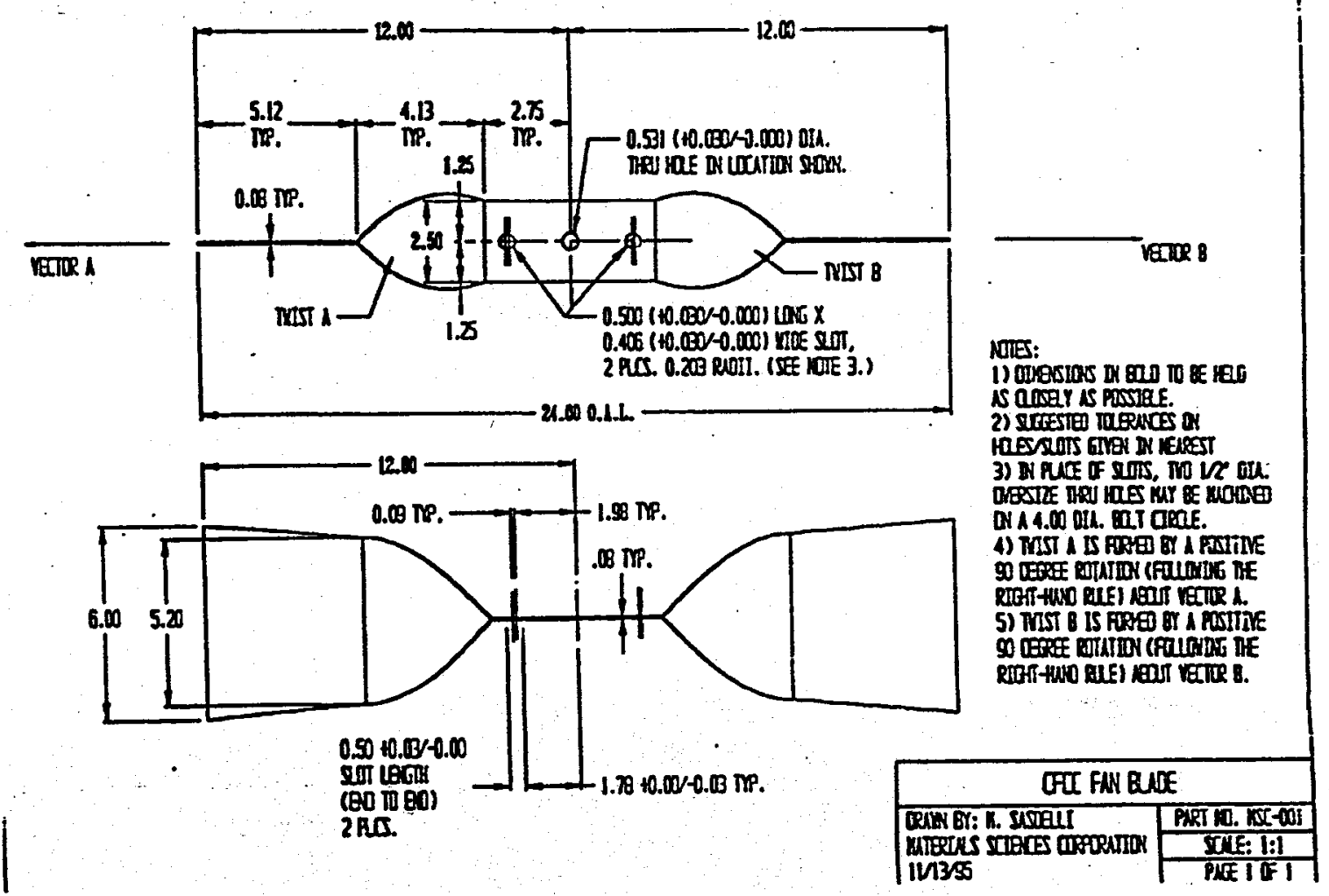

MSC drawing of a CFCC hot gas fan blade segment. 


\title{
Fabric Deformation Experiments
}

Several fiber types as well as various weave constructions were evaluated. These included:

\author{
Nextel 312 Plain Weave, Crow Foot, 5HS \\ Nicalon Ceramic Grade Plain Weave, 8HS and
}

\section{Altex 8HS}

Although the baseline fiber was Nicalon, cost considerations permitted the screening of less expensive fiber alternatives. Each candidate weave was cut into several rectangular plies for the forming experiments.

Initially, single fabric plies were retained between plywood plates at the hub and blade regions, with the twist region unrestrained. The blade section was then rotated $90^{\circ}$ with respect to the hub region and the fabric deformation within twist region was qualitatively evaluated. As might be expected, the plain weaves did not fare very well. The resistance of tow to tow slippage caused sever fabric buckling. All attempts to promote slippage within the plain weave proved fruitless. The Crow Foot and 5HS also experienced fabric bucking, but to a lesser extent. Both $8 \mathrm{HS}$ weaves deformed well and were selected for continued study; there appeared to be no formability difference between the Nicalon 8HS and the Altex 8HS.

Preliminary weave evaluation, with the plywood plates, answered the most basic formability questions. However, the fabrics ability to exactly conform to the fan blade twist had yet to be demonstrated. For this evaluation the completed cold tool was required. As the computer models and cold tooling preliminary designs evolved, so did the starting shape of the preform. Instead of rectangular preform plies, bow tie plies had evolved. This shape resulted when the width of the hub region was reduced to 2.50", while maintaining $6.00^{n}$ wide paddle blades. Within the hot gas fan twist region, the preform had to accommodate a $90^{\circ}$ rotation and a preform width change from $2.50^{\prime \prime}$ to

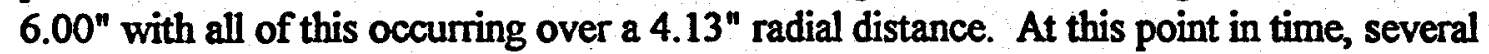
plies of both Nicalon 8HS and Altex 8HS were cut into the bow tie shape and awaited delivery of the cold tool.

\section{Cold Tool Design and Fabrication}

With the design of the component geometry fully defined, MSC's computer model was forwarded to a local Catia design house. Several days were schedule for the Catia designer, the trapped rubber tooling consultant and a representative from Amercom to model the trapped rubber tool. During this process the tool offsets are established, 
thermal expansion factors incorporated, the volume and placement of the rubber cavities are established and the bulk tool dimensions are defined. The tool was designed to produce an oversized fan blade segment (all dimensions except thickness) to allow for preform cutting variations and allow for complete edge clean up during final machining. In the case of the hot gas fan blade segments, one-half inch of excess material was allowed in tool design. The next design step separates the tool into individual components that allow for preform loading, easy tool closure, tool locking for rubber containment, tool disassembly and, most importantly damage free removal of the rigidized preform.

The Catia design house was given the contract to machine the metallic components of the trapped rubber tool. The Catia operator programmed the cutting tool motions to manufacture each metallic component and these instructions were fed into a multi-axis machining station. All machining was performed by $\mathrm{CNC}$ machines; no drawings were ever created for the hot gas fan cold tool. The design and manufacture of the hot gas fan cold tool is a perfect example of this country's current technology in paperless design and manufacturing.

The rubber tool components are formed from a pourable rubber compound using the finished metal cold tooling components as the mold. When the metallic cold tooling components were received from the Catia facility, a wax model of the fan blade preform was placed into the tool. The tool was then closed. The pourable rubber was introduced into the tool cavity through properly placed holes in the tool frame; these holes were subsequently plugged for cold tooling operations. Once the rubber had set, the tool was disassembled and the rubber removed. Following an air cure, the rubber tooling segment was oven cured per the manufactures specifications. Finally, the wax fan model was removed and the tool was ready for use.

This particular tool was complicated slightly by the design requirement that each hub to blade transition have the same twist direction (right-hand vs left-hand) when viewed from any given position. In order to form this shape and maintain a fundamental trapped rubber tooling axiom (one side of the preform must be solely in contact with a hard machined surface while the other preform side be solely in contact with a compliant rubber surface) two pieces of rubber were required. During lay-up one rubber segment would be placed into the tool as the first operation. Next, the preform would be molded into the tool, part on top of the rubber and the remainder into the machined metal portions of the tool. Lastly, the second rubber piece would be positioned over the preform, simultaneously making edge to edge contact with the first rubber piece. While this procedure is difficult to describe, it did work quite well in practice.

\section{Preform Evolution}

Once the cold tool arrived, forming experiments with fabric plies continued. Based on fabric cost and the fact that first articles tend to be of lesser quality, experiments began 
with the Altex material. The cold tooling compounds were prepared and five Altex plies were dipped, one at a time and loaded into the tool. Fabric distortion through the transition region looked good and only minimal hand work of the fabric was required to achieve complete adherence to the tool geometry. One problem in tool loading was noted: This was an unraveling of the weave through the transition region where the fill fiber tows were cut at a small angle (approximately $23^{\circ}$ ) as measured from the fill direction. This allowed fill tows to unravel from the warp. This in turn allowed the warp tows to wander off-axis. The preform edges in the transition regions became very difficult to manage. An engineering review of the cutting procedure, ply handling procedure and tool loading procedure exposed no deficiencies. We concluded that the fabric simply could not be distorted without unraveling given the bow tie shape.

In the past Amercom has used stitching techniques to manage difficult preforms. Rectangular fabric plies of both Altex and Nicalon were cut and paper patterns were printed as a sewing guide. The preform plies were stacked to full preform thickness, five plies of Altex or seven plies of Nicalon, and covered with a paper sewing guide. These materials were delivered to a local high temperature sewing company (ceramic stitching for rocket engine insulation and space blankets, etc.) for stitching trials. Amercom engineering was present to guide and evaluate the stitching effort. After several iterations, it appeared that a zig-zag stitch around the perimeter of the bow tie shape and $2 \times 2$ quilting over the entire preform surface would allow adequate distortion of the preform packet while maintaining edge control of the preform. Nylon sewing thread was chosen for all stitching. It should be noted that the zig-zag stitch was to be placed in the trim region of the preform. In this location, cutting of the bow tie shape will be done outboard of the stitch and machining of the final hot gas fan blade will be done inboard of the stitch; there will be no residue from the zig-zag stitch in the final CFCC hot gas fan. Several of these stitched preform packets were assembled for blade forming trials.

Once at Amercom, the preform packets were cut into the bow tie configuration and the remaining paper sewing guide was burned off of the preform packet; no unraveling of any fabric plies was noted during these handling operations. The preform packets were dipped in the cold tooling compound and molded into the tool. The speed at which the tool could be loaded was greatly improved. The early experiments with individual plies would take an engineer and a technician between one and two hours each. With the preform packets the tool could be loaded by a single individual in about 20 minutes and the quality of the loaded preform was higher; there was no preform unraveling during tool loading. Several representative hot gas fan blade segments were made, using the stitched preform packets, with great success. This preform preparation technique was adopted for all subsequent hot gas fan preforms. 


\section{Representative Parts}

In total, six hot gas fan blade segments were formed. Five were reinforced with Altex and one was Nicalon reinforced. All segments were cold tooled using stitched preforms and densified without tooling to debulk the preform. Densification was accomplished, three fan segments at a time, on a graphite plate suspended in the CVD reactor. The plate had a vertical center post for preform/composite location and six sets of two vertical rods at $60^{\circ}$ rotation around the plate circumference. The spacing of each vertical rod pair was equal to the fan blade thickness. With this plate arrangement we were able to load a fan blade preform onto the center locating shaft and then vertically stabilize the segment paddles by placing the paddles through two diametrically opposed vertical rod pairs. Next, a oneinch spacer was place on the center locating rod and another blade preform was loaded at $60^{\circ}$ with respect to the previous preform. Three blades, or one complete hot gas fan, could be co-processed using this suspended plate approach.

The photograph below shows three blade segments arranged in the hot gas fan configuration. The lightest colored segment is a cold tooled Altex preform, this segment has no $\mathrm{SiC}$ matrix present. The next segment (clockwise) is a fully densified Altex blade, this blade is ready for machining. The third blade segment is a cold tooled Nicalon preform, this segment has no SiC matrix present.

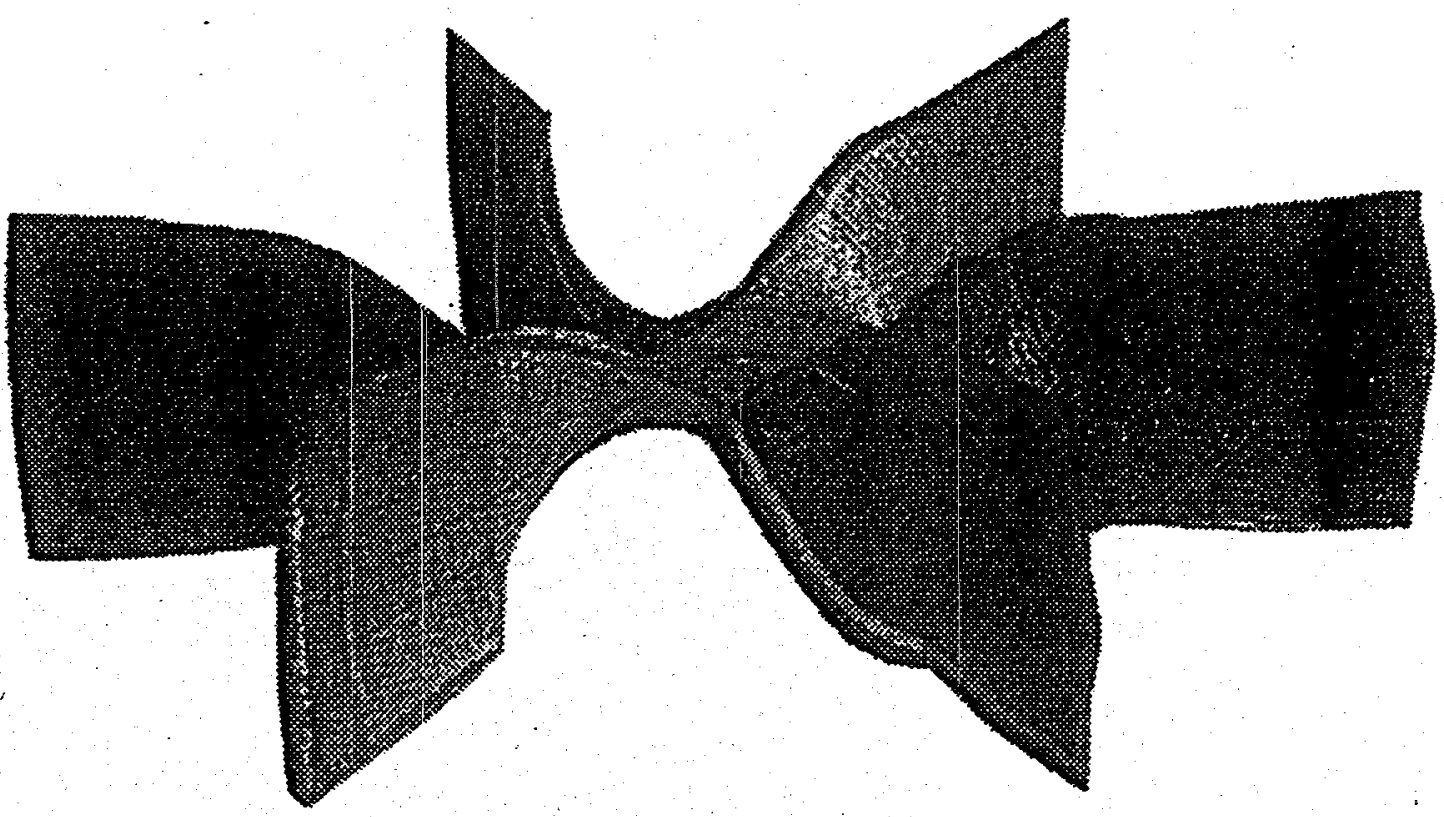

Following the first infiltration run with three Altex fan blade preforms in this arrangement, careful inspection was performed to verify that the preforms had not distorted during heatup and initial infiltration; no discernable change in blade geometry was noted. The densification process continued with these first three preforms. When complete, these 
blade segments were delivered to a water jet cutting facility for machining; see the next section for a summary of the machining operations.

Once the first set of blade segments completed the densification process, a second set of blade segments began the densification process. This CVD batch was comprised of two Altex preforms and one Nicalon preform. This material lot was not intended to form a second CFCC fan, but rather each segment was to be used for a specific purpose. One of the Altex segments and the Nicalon segment were planned for tensile strength and elongation comparison. Dogbone tensile specimens were to be cut from both the hub and paddle regions of these components and then tensile tested to determine room temperature mechanical properties. The third Altex blade segment was scheduled for delivery to Argonne National Laboratory (ANL) for thermal and ultrasonic imaging. This type of imaging was expected to reveal the quality of ply lamination resulting from our cold tooling process.

At the time of Amercom closure, five blade segments were at Amercom. Three Altex blade segments had been returned from the water jet machining facility, however, machining of the hub bolt holes was still pending. Also at Amercom were an as-fabricated Altex blade segment and an as-fabricated Nicalon blade segment that were both pending machining of tensile bars. The sixth blade segment (Altex) was at ANL awaiting both thermal and ultrasonic imaging.

\section{Machining and Dimensional Conformance}

Various forms of machining were evaluated for hot gas fan machining. Conceptually, we were cutting a coupon from a larger plate; the complication was that the plate was nonplaner. The fact remained that all that had to be accomplished was through-the-thickness machining of a composite plate and the most cost effective technique for this type of machining was water jet cutting. A water jet machining vendor review was initiated; the twisted plate shape required a sophisticated multi-axis machining station with a water jet cutting head. A qualified vendor was found in the Los Angeles area. Following an introductory meeting, the vendor was approved based on technical skills and production equipment.

The same MSC 3-D computer model that was used for cold tool generation was also forwarded to the selected water jet machining vendor. From this model, the cutting motions were programed into the machining center. Special fixtures were fabricated to hold and support the CFCC component during cutting. The last step in the vendor's setup was to verify cutting speed (i.e. quoted cost) by cutting trials on similar material. Amercom supplied a sample of Nicalon/SiC plate that was similar in thickness to the fan blades; the substitution of Nicalon for Altex in the machining trial was not deemed significant. Cutting trials resulted in actual cutting speeds slower than those used to prepare machining estimates; the quotation was revised. Finally, prototype Altex blade 
segments were delivered for machining. The Altex reinforced CFCC components cut at the expected rate. The machining characteristic for Altex reinforced CFCCs were virtually identical to those of Nicalon reinforced CFCCs.

As machining progressed, the vendor reported two anomalies: 1) the twist region was outof-form and 2) machining to the computer model dimensions did not result in a complete clean-up of the component perimeter. While anomaly " $\mathrm{H1}$ " could have led to anomaly "\#2," this was not the case for the CFCC blade segments; the source of the anomalies were distinctly different.

The out-of-form condition in the transition regions could have resulted from a discrepancy, or translation error between any one of the three models used to go from concept to component. This event is usually unlikely; however, this was the first collaboration for the three parties involved (MSC, Catia design and water jet machining) and Amercom was aware of some program-to-program translation difficulties. Another, equally likely event, was that some relaxation of the preform occurred between cold tooling and rigidization. The techniques used to check for this type of movement were qualitative and could have easily missed movement of one or two millimeters over a twisted surface. The affect of this out-of-form condition was a tapered edge $\left(<10^{\circ}\right.$ from normal) through the transition region. This taper caused no problems for the machining vendor and resulted in no foreseeable performance problems from the end-user's point of view. The anomaly was deemed insignificant. Steps to investigate the source and eliminate the anomaly were planned for the next cold tooling design iteration.

A more significant issue was the undersized condition of the current prototypes. The undersized condition prevented full clean-up of the paddle blade width (blade height) and radial length (blade length); the transition and hub regions were not undersized in the current blade configuration. Since the first article was a "show piece" a decision was made to reduce the physical dimensions of the paddle section to allow full clean-up of the composite perimeter. The first three blade segments were delivered with an overall diameter of $23.0^{\prime \prime}$ (one-half inch shorter on each paddle length) and a paddle blade height of 5.5" (one-half inch shorter than "print," one-quarter inch short on each paddle edge.) These clean-up dimensions were based on the minimum dimensions of each of the three supplied blade segments. Since all three initial fan blade segments were machined to the same minimal clean-up profile, balancing trials could be performed on this blade set.

\section{Proposed Simulation Tests}

During the design and first article fabrication operations of the CFCC hot gas fan blade segments, Surface Combustion was designing and fabricating a refractory metal shaft to index and hold the three segment CFCC hot gas fan blade assembly. This shaft design was consistent, and the result of MSCs hot gas fan design. The material used by Surface Combustion for shaft fabrication was a 600 series Inconel. 
The program's simulation test plan called for:

Slow and cold spin tests to check balance.

Full speed cold spin tests for balance and mechanical performance evaluation.

Hot testing for endurance, with some overspeed to verify the material's safety margin, at Surface Combustion's in-house test facility (an actual BIQ furnace).

Pending successful completion of the simulation tests, the prototypical CFCC hot gas fan would be delivered to a preselected Surface Combustion customer with a BIQ furnace for end-user service testing. The prototype fan would be installed in the furnace during a routine maintenance cycle and then the furnace would be returned to service. Although a specific customer was never identified, the area around SC's facility is heavily involved in heat treating for the automotive industry. The plan was to use one of the local heat treatment facilities for end-user service testing.

The first task in the test plan was balancing. The cast alloy fans were delivered to SC prebalanced and ready for installation. The vendor added mass by welding Inconel bars to the appropriate paddle blade until balance was achieved; this option was not open to a CFCC fan. Amercom engineering investigated methods to balance both the individual blade segments and the assembled fan. The options were limited. The dynamic engineers cautioned that balancing each individual blade segment would not guarantee a balanced assembly. The dynamic balancing organizations that were contacted were not capable of balancing a CFCC fan assembly and could not tell us where to add, or remove material to achieve balance. Ideally, we were looking for a vendor that could spin the fan assembly, then report a physical location on the assembly and say "Remove 20 grams from here." We never found a vendor who could do this. Amercom engineering needed to become much more familiar with balancing techniques and begin to work with one specific vendor to develop this capability.

One final comment with respect to balancing; some engineers felt that given the current configuration (metallic shaft and CFCC blades) balancing may not be required. The fact that the shaft was so massive with respect to the three CFCC blade segments and the shaft is balanced by virtue of lathe machining, any small imbalance created by the blades would not be noticed in the massive rotating system. Even if this theory proved true, it would only apply to the interim hot gas fan design (metallic shaft and CFCC blades) and eventually the all CFCC fan would most certainly require dynamic balancing. For this reason, dynamic balancing capability for CFCC material is a necessary technology and must be developed. 
It was a this point in the CFCC hot gas fan development that work was stopped at Amercom. The mounting holes were never machined into the first set of three fan blade segments and, therefore, the first CFCC hot gas fan was never assembled.

\subsubsection{Hot Gas Filters}

Industrial Filter and Pump Manufacturing Company, Inc. (IF\&P) of Cicero, Illinois was our OEM for the CFCC hot gas filter development. Hot gas filters are used primarily in the coal fired power generation industry. They are placed between the combustion source and the generator's turbine. Their job is to trap entrained particles in the combustion gas and protect the turbine from particulate damage. Several types of hot gas filters are currently available. Unfortunately, the combustion temperature of emerging advanced power generation cycles (IGCC and PFBC) are too high for the majority of available filter materials. In this situation, the combustion gas must be cooled prior to filtration. When the combustion gases are cooled a loss of system efficiency results, which in turn increases the cost of electricity and decreases the benefit of the advanced power cycle.

One type of filtration system that does not require cooling is a candle filter system. A typical candle filter is a tube, closed at one end, with a $60 \mathrm{~mm}$ outside diameter, $40 \mathrm{~mm}$ inside diameter and an overall length of $1500 \mathrm{~mm}$. Usually, some type of flange arrangement is provided on the open end to accommodate mounting and sealing. These tubes can be constructed of various materials and many are made from reaction bonded $\mathrm{SiC}$. Candle filters are suspended vertically from tube sheets in a pressure vessel. A tube sheet is a gas barrier between the "clean" and "dirty" regions of the pressure vessel with machined holes and recesses to accommodate the candle filters. The number of candle filters in a system varies based on the design requirements of the power generation system. However, a practical limit occurs within the tube sheet's ability to carry the candle filter load. Reaction bonded $\mathrm{SiC}$ candles weigh in excess of seven kilograms each. Tube sheets for these candles are thick, heavy and drive the structural requirements of the system.

IF\&P has a very unique candle filter technology. Their candle filter is manufactured by vacuum forming chopped ceramic fibers with a proprietary binder, this material is called Fibrosic $^{\mathrm{tm}}$. IF\&P's filter dimensions are identical to the reaction bonded $\mathrm{SiC}$ versions, however the Fibrosic ${ }^{\mathrm{mm}}$ filters are much lighter. A $1500 \mathrm{~mm}$ IF\&P Fibrosic ${ }^{\mathrm{mm}}$ candle filter weighs about one kilogram. Another advantage of the Fibrosic ${ }^{\mathrm{m}}$ candle filters is its thermal shock resistance as compared to the reaction bonded $\mathrm{SiC}$ products. IF\&P also uses the Fibrosic ${ }^{\text {tm }}$ material for their tube sheets which significantly reduced the mass of their candle filter systems. Each of these attributes is a competitive advantage for IF\&P and the wide industry acceptance of their product demonstrates industry approval.

The Achilles' heel of the Fibrosic ${ }^{\text {m }}$ candles is their tensile strength. As they currently exist they can carry all of the normal operating loads at combustion temperature. These loads include: static loads (i.e. their own weight), dynamic gas loading caused by the filtration 
process, dynamic gas loading caused by jet pulse cleaning as well as stresses created by thermal gradients during start-up, shutdown and jet pulse cleaning. The problem occurs when bending stresses are applied to the candle filter flange region. The tensile side of the bend fails catastrophically. Sometimes the tube is severed and falls and sometimes the crack arrests without the tube falling. In either case, a particulate path has been created between the combustion process and the turbine; the power generation process must be immediately shutdown to avoid irreparable damage to the turbine. The cause of this bending is a phenomenon called bridging.

Bridging is the situation where the accumulated filter cake from adjacent candle filters "grows" together, makes contact and begins to apply forces to the suspended candles. Since the candles are suspended at the top and free at the bottom, bending stresses occur in the flange region at the top. Jet pulse cleaning is intended to remove the filter cake accumulation, however a residual cake will typically form at the candle filter bottoms. This residual cake is the source of bridging and ultimately the source of catastrophic tube failure. It should be noted that bridging also occurs in candle systems with reaction bonded $\mathrm{SiC}$ candies; the phenomenon is process related and not a function of the candle filter material. However, the greater tensile strength of the reaction bonded material makes these materials less susceptible to catastrophic failure from bending.

Our CFCC task was to toughen the existing Fibrosic ${ }^{\text {th }}$ candle filter without deteriorating its filtration properties. The existing product was very good and widely accepted by the power generation industry, it just needed to be a little tougher.

\section{Component Design}

Our approach was to reinforce the vacuum formed filter with a CFCC skeletal structure. Meetings were held to brainstorm various approaches. The leading idea was to fully embed a filament wound CFCC structure within the $10 \mathrm{~mm}$ thick tube wall. Complete encapsulation maximizes the contact area between the CFCC structure and the vacuum formed Fibrosic ${ }^{\text {tm }}$ which will maximize load transfer and minimize fretting. Further, embedding the structure toward the annular interior will provide some CFCC protection from the corrosive and oxidizing combustion gases. With respect to the selected structure, filament wound structures can be easily controlled to achieve a very open winding pattern. Furthermore, the open pattern eases CVD infiltration difficulties usually associated with filament wound structures. The following filament wound structure was arrived at, somewhat arbitrarily, as the beginning structure for candle filter reinforcement:

$2 \mathrm{~mm}$ total band thickness by $3 \mathrm{~mm}$ band width,

$10 \mathrm{~mm}$ offset or stagger with zero lead, $\pm 45^{\circ}$ wind angle with a 
$42 \mathrm{~mm}$ internal diameter.

This structure became known as a CFCC strongback.

The CFCC strongback dimensions, the bulk dimension of the candle filter, material properties for Fibrosic $^{\mathrm{m}}$ and the operational parameters for a typical hot gas filter system were forwarded to MSC. MSC was asked to preform a FEA on the proposed strongback reinforced candle filter.

MSC's analysis determined that the maximum stresses in the CFCC strongback were approximately $0.4 \mathrm{MPa}$ (tensile) for the internal pressure condition (jet pulse), and 1.4 $\mathrm{MPa}$ (compressive) for the external pressure load (normal filtration.) The thermal loads generated an additional 0.6 MPa (tensile.). These results showed the effectiveness of the strongback in absorbing the pressure loads that would otherwise have gone to the weaker filter material.

MSC went on to caution that "Any failures in the integrated design are likely to be the result of filter/strongback separation due to the development of high (relative to material strengths) shear stresses at the filter/strongback interface at each end of the filter. These shear stresses were found to occur during external pressure and thermal load condition. The thermal load being more severe." And, "These shears were the result of both geometry and material property discontinuities at these locations, and could not be eliminated by uniformity of material alone. However, given the nature of the filter material, localized shear stresses may be accommodated by local yielding of the filter material."

After reviewing the MSC analysis, we concluded that the current design was valid. Operational stresses were very low. We responded to MSC's concern by including a number of "fast" thermal cycle tests in the simulation test plan. Post thermal cycle analysis would look specifically for evidence of filter/strongback disbond. With this amendment to the test plan we commenced fabrication of CFCC strongbacks.

\section{Tooling Options}

In order to be cost competitive, cold tooling would be required for production articles. However, with the almost certain geometric changes that occur as a CFCC develops from concept to hardware, we opted for hot tooling at this early stage. The prototype candle filter elements were full scale in all radial dimension, but only $330 \mathrm{~mm}$ in overall length; all flange dimensions were full scale. Toyo Tanso's SIC- 6 grade graphite was selected as the hot tooling material for the lot \#1 strongback prototypes. Graphite mandrels were fabricated and the first lot of CFCC strongbacks were densified on these mandrels. Unfortunately, of the dozen lot \#1 strongbacks, only eight were successfully removed 
from the graphite mandrels; the remaining four were permanently bonded to the mandrels with $\mathrm{SiC}$.

Another mandrel design was prepared, this time using Toyo Tanso's ISO-88 grade graphite. The higher thermal expansion of the ISO-88, over SIC-6, would provide more radial movement after the initial CVD process and lessen the chance of preform/mandre] bonding. Lot \#2 consisted of eighteen strongback preforms on ISO-88 mandrels. Post processing, twelve CFCC strongbacks were successfully removed from the mandrels, six were permanently bonded to the mandrels and lost.

A third iteration on the mandrel design was carried out. This time, in addition to the benefit of high expansion graphite, a slight taper was added to the cylindrical portion of the mandrel. Fifteen preforms were filament wound on the mandrels (lot \#3) and densified. Mandrel removal was successful on eleven of the fifteen lot \#3 strongbacks, however, two different fiber reinforcements were used in lot \#3. Differences in the physical properties of these two reinforcements most likely played a role in mandrel separation behavior. See the next section "Preform Development" for an explanation of the different reinforcement materials.

It should be noted that production cold tools for this type of geometry are usually collapsible, cylindrical mandrels and typically would not suffer from the same problems encountered with the graphite tools. However, they could have a set of problems all of their own. At this stage of the development we were not concerned with cool tooling development. Our focus was simply to produce functioning prototypes for CFCC strongback demonstration.

\section{Preform Evolution}

Concurrent with the mandrel evolution outlined in the previous section, the preform was undergoing an evolution of its own. Initially the strongback was to occupy an annular region within the candle filter with only $1 \mathrm{~mm}$ of Fibrosic ${ }^{\mathrm{m}}$ coverage over the strongback I.D. This was the design point for the lot \#1 strongbacks. Of the eight lot \#1 strongbacks that completed the densification, only two were sent to IF\&P for vacuum forming trials. The balance of six were consumed in qualitative mechanical tests for uniformity, filament winding evaluations and "show pieces." Filament winding evaluation showed some filament winding lead from layer to layer. Lead is a constant axial offset of sequential filament winding passes (layers) caused by the fact that as the filament wound structure "grows," the radius at which the filament meets the structure is increasing. In the strongback preform this resulted in gas flow paths that were not normal to the surface. This reduced the projected flow area through the strongback and would have had an adverse effect on filter performance. The vendor was contacted and asked to produce preforms with zero lead. The vendor was unable to produce such a preform and new vendor evaluations began. 
Prior to CFCC strongback lot \#2, IF\&P's vacuum former had successfully produced

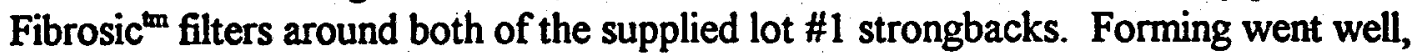
however, the strongbacks wandered during forming and both strongbacks solidified with their centerline's skew to the Fibrosic ${ }^{\text {tm }}$ centerline; both strongbacks were exposed at some interior location of both Fibrosic ${ }^{\mathrm{m}}$ filters. Comments from the vacuum former were generally positive and they felt that they could better control the position of the strongback with some additional development. In order to ease the burden on the vacuum former, Amercom initiated a design change to move the location of the strongback more toward the annular center of the candle filter. This change in strongback position would allow some centerline skew without strongback penetration of either the interior or exterior Fibrosic ${ }^{\mathrm{m}}$ surfaces. The vacuum former agreed with the proposed change and IF\&P approved the change in strongback position. The lot \#2 mandrels were designed to position the strongback at an I.D. of $45 \mathrm{~mm}$. Twenty-four mandrels were ordered. By the time the lot \#2 mandrels were ready for winding, Amercom had found a new filament winding vendor that could produce the required preforms with zero lead. An order for eighteen preforms was placed with the new vendor.

Lot \#2 preforms were received and measurements verified that the new vendor had supplied "zero lead" preforms. All eighteen lot \#2 strongbacks were densified. Of the eighteen lot \#2 strongbacks, twelve were successfully removed from their winding mandrels. Ten of theses strongbacks were delivered to IF\&P for vacuum forming, the other two were sectioned to evaluate fiber bundle placement and infiltration quality.

Lot \#3 mandrels incorporated a cylindrical taper (approximately $0.15^{\circ}$ ) over the long cylindrical portion of the strongback. This taper was intended to aid in the release of the strongback from the winding mandrel after initial processing (see previous section "Tooling Options"). The filament winding vendor was briefed on the change in mandrel geometry and asked if they could produce zero offset preforms on tapered mandrels. They indicated that after a nonrecurring engineering charge for programming, zero offset tapered preforms could be produced.

Prior to lot \#3, all strongbacks (lot \#1 and lot \#2) were wound using four unserved ends of 1800 denier Nicalon. Five filament winding passes were required to build the required preform thickness of $2 \mathrm{~mm}$. During preform evolution, and concurrent with the hot gas fan forming experiments, Altex fiber was emerging as a viable alternative to Nicalon. In order to evaluate Altex as a strongback reinforcement, lot \#3 would include both Altex and Nicalon reinforced strongbacks. Preliminary wind design suggested that five passes with two unserved ends of 5000 denier Altex would produce a suitable structure. The filament winding vendor concurred with the filament winding approach. Amercom placed an order for ten Altex strongbacks and five Nicalon strongbacks; fifteen mandrels along with continuous spools of both Nicalon and Altex were delivered to the winding facility. 
When the lot \#3 preforms were delivered to Amercom, they were inspected. All design requirements had been met. These fifteen preforms were densified as strongback lot\#3. Mandrel removal was successful for nine of the ten Altex strongbacks, but only two of the five Nicalon strongbacks were successfully removed from the winding mandrel. The higher coefficient of thermal expansion for the alumina based Altex, as compared to the SiC based Nicalon, probably played a major role in successful mandrel release for the Altex strongbacks. All nine Altex and both Nicalon strongbacks were deliver to IF\&P for vacuum forming and testing.

With respect to the recurring problem of the Nicalon strongbacks sticking to their winding mandrels, CVD process variations would have most likely been implemented to limit the $\mathrm{SiC}$ deposition prior to mandrel removal. Further mandrel development would probably have been too costly, since the next mandrel design iteration would require segmented and collapsible mandrels. The program ended before any further mandrel and/or process changes were developed.

\section{Representative Parts}

The following table summarizes strongback deliveries to IF\&P for vacuum forming and simulation testing:

\begin{tabular}{|c|c|c|}
\cline { 2 - 3 } \multicolumn{1}{c|}{} & $\begin{array}{c}\text { Nicalon } \\
\text { strongbacks }\end{array}$ & $\begin{array}{c}\text { Altex } \\
\text { strongbacks }\end{array}$ \\
\hline Lot \#1 & 2 & 0 \\
\hline Lot \#2 & 10 & 0 \\
\hline Lot \#3 & 2 & 9 \\
\hline \hline Total: & 14 & 9 \\
\hline
\end{tabular}

All lot \#1 and lot \#2 strongbacks were vacuum formed with Fibrosic ${ }^{\mathrm{m}}$ and machined into "short" $330 \mathrm{~mm}$ candle filter elements. Several of these components have undergone simulation testing at IF\&P (see the next section). The photograph on the following page shows a lot \#1 strongback with the vacuum formed Fibrosic ${ }^{\text {mm }}$ removed from the upper portion and flange region of the candle filter. This candle filter is full scale in all diametral dimensions, but only $330 \mathrm{~mm}$ long.

The lot \#3 strongbacks were shipped from Amercom on January 6, 1997. IF\&P acknowledged receipt of this shipment. However, by the date of program shutdown, there was no report from IF\&P that lot \#3 strongbacks had completed vacuum forming and/or machining. It is assumed that lot \#3 strongbacks are in storage at the IF\&P facility. 


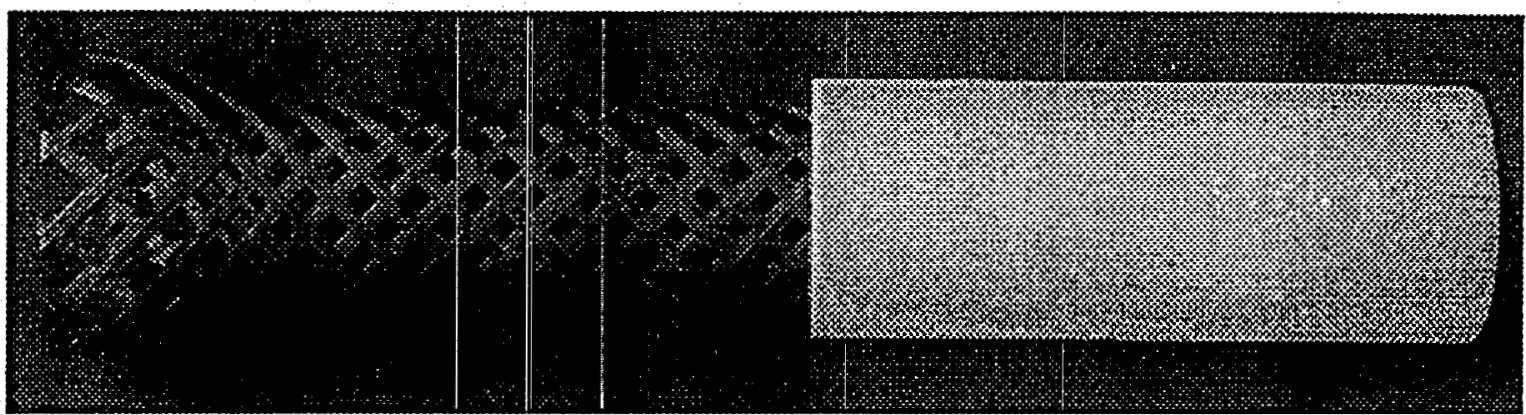

$330 \mathrm{~mm}$ strongback reinforced candle filter. Fibrosic ${ }^{\text {tm }}$ removed from the top (left) half to expose the strongback.

\section{Simulation Testing}

The original simulation test plan for strongback reinforced candle filters consisted of the following tests.

Profile testing - a room temperature, clean gas test to evaluate the pressure differential across the strongback candle filter wall as a function of volumetric flow rate.

Dust trials - a room temperature, "dirty" gas test to evaluate the pressure differential across the strongback candle filter wall as a function of volumetric flow rate. This test will be conducted with various dusts (each, the actual ash from an existing coal fired power plant) at various dust loading levels. The test apparatus will be capable of reverse jet pulsing to simulate the candle filter cleaning operation of an actual hot gas filter system.

Hot flow testing - elevated temperature $980^{\circ} \mathrm{C}$, "dirty" gas test to evaluate the pressure differential across the strongback candle filter wall as a function of volumetric flow rate. This test will be conducted with various dusts (each, the actual ash from an existing coal fired power plant) at various dust loading levels. The test apparatus will be capable of reverse jet pulsing to simulate the candle filter cleaning operation of an actual hot gas filter system. In a hot gas test, the jet pulse produces a steep thermal gradient through the candle filter wall. Thermal shock behavior will also be evaluated during hot flow testing.

Destructive test - Bend, burst and crush tests to determine the remaining strength of the strongback reinforced candle filters after hot gas testing. These strengths will be compared to existing data for non-reinforced candle filters after this type of exposure.

As previously mentioned, thermal cycle testing was added to the simulation test plan. The thermal cycle test consists of five cycles from room temperature to $980^{\circ} \mathrm{C}$ and back to room temperature at a controlled ramp rate of $170^{\circ} \mathrm{C} /$ hour. These ramp rates are more severe than typically experienced by operational candle filter systems. Following the test, 
the strongback reinforced filters would be sectioned to evaluate the bond/disbond of the strongback to the vacuum formed Fibrosic ${ }^{\mathrm{m}}$. This test was inserted between the profile test and the dust trials in the test plan.

By program's end, simulation testing had progressed through hot flow testing, however, safety issues with the newly installed facility limited the gas preheat temperature to $700^{\circ} \mathrm{C}$. This resulted in a filter vessel temperature of only $260^{\circ} \mathrm{C}$ as compared to the target test temperature of $980^{\circ} \mathrm{C}$. Even though full temperature hot flow testing was not performed, this test and all previous tests were declared successful. The results of these tests are presented below.

\section{Profile Test Results}

The profile test was performed on a lot \#1 reinforced candle filter and compared to existing data for unreinforced Fibrosic ${ }^{\text {tm }}$ candle filters. The test was performed at various face velocities from zero to $40 \mathrm{feet} /$ minute; these face velocities are based on a $0.46 \mathrm{ft}^{2}$ effective filtering area. At each discreet face velocity, the $\Delta \mathrm{P}$ through the candle filter wall was measured. The graphical results are shown on the following page

The graph shows an increase in filter $\Delta \mathrm{P}$ with the presence of the reinforcing strongback; this was not unexpected. The $\Delta \mathrm{P}$ increase was approximately $15 \%$ at the higher face velocities. The test report from IF\&P stated: "The small increase in delta $P$ is considered acceptable if the filter's useful life is increased. This test was considered a success."

\section{Thermal Cycle Test Results}

The thermal cycle test was performed on the second, lot \#1, reinforced candle filter. Five complete thermal cycles, from ambient to $980^{\circ} \mathrm{C}$ and back to ambient temperature, were performed. Both the rise and fall ramp rate for these cycles was controlled at $110^{\circ} \mathrm{C}$, as opposed to the planned $170^{\circ} \mathrm{C}$, to better mimic conditions found in many actual filter applications. Visual inspections were performed after each complete cycle. The test report from IF\&P stated: "Even after 5 complete thermal cycles, no evidence of cracking, buckling, or delamination of the strongback Fibrosic ${ }^{\text {tm }}$ prototype was observed."

The thermal cycle test was successfully passed. The original plan was to section the thermal cycle test article to perform a detailed evaluation of the bond/disbond between the strongback and the vacuum formed Fibrosic ${ }^{m}$. However, with the limited number of test articles and the fact that no observable damage occurred during thermal cycle testing; the destructive evaluations were omitted and this prototype candle filter was scheduled for dust trials. 


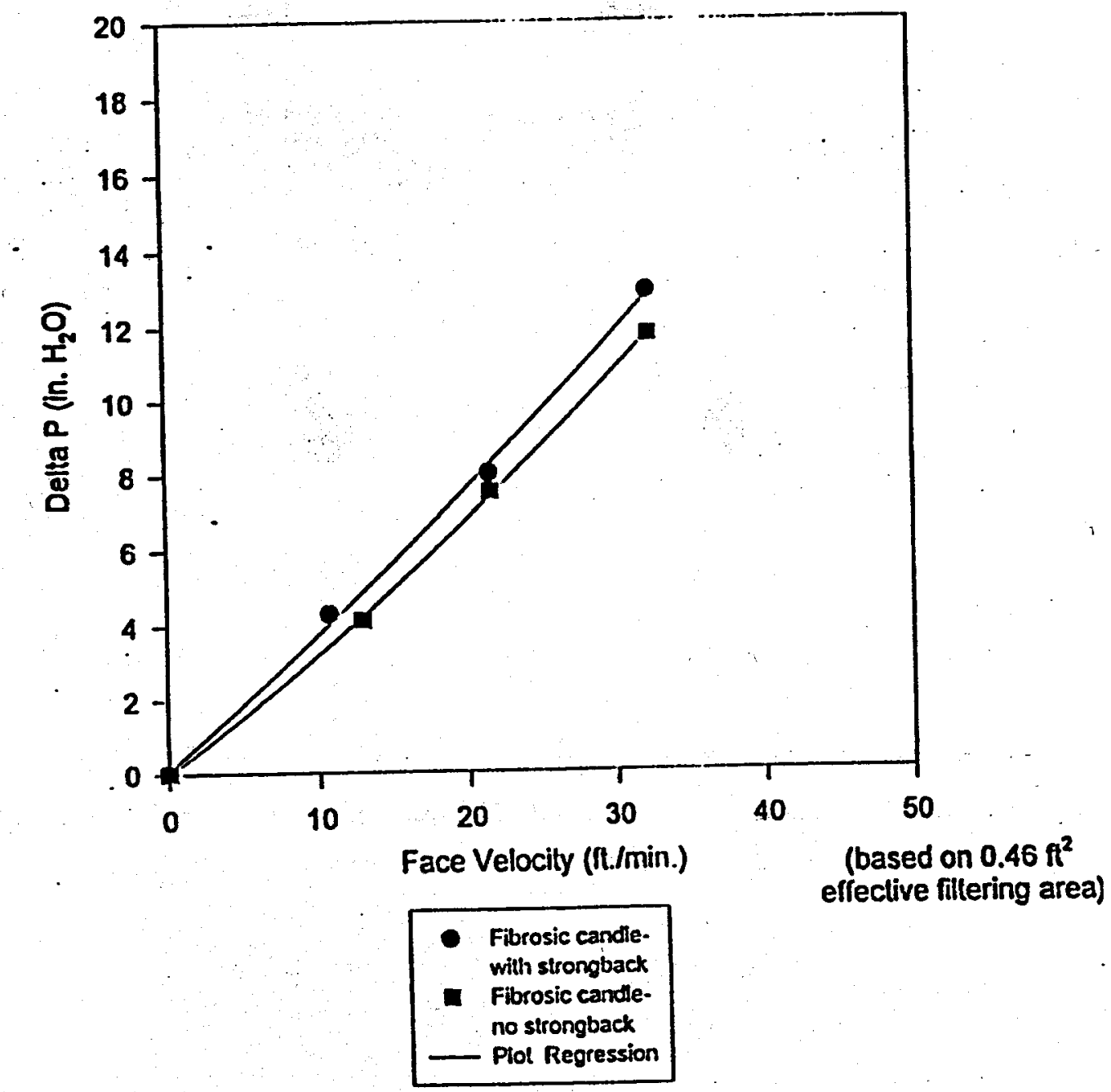

Fibrosic $^{\text {m }}$ candle filters with and without CFCC strongback reinforcement.

\section{Dust Trial Test Results}

The prototype candle filter, from the thermal cycle test (second article of lot \#1 strongbacks), was paced in IF\&P's dust trial test facility. Cyclic testing of this candle filter was performed using 150 grams of Eagle-Picher $M N-23$ diatomaceous earth dust to 
simulate the particle size and particle distribution typically encountered in candle filtration. This dust was entrained in ambient air at $140 \mathrm{lpm}$ (5 SCFM) and delivered to the exterior surface of the test filter. A $620 \mathrm{kPa}$ (90 psig) supply of nitrogen was used for jet pulse cleaning of the test article which took place at five minute timed intervals.

IF\&P reported tabular data with the candle filter's $\Delta \mathrm{P}$ both "just before" and "just after" jet pulse cleaning. Tabular data covered 92 jet pulse cleaning cycles, or a test duration of seven hours and 40 minutes. The candle filter's $\Delta P$ stabilized at approximately twentyseven inches of water after 70 cycles, or 5 hour and 50 minutes into the test. The $\Delta P$ stabilization at 27 inches of water column and the time it took to achieve stabilization are both considered nominal for a Fibrosic ${ }^{\mathrm{mm}}$ candle filter. There was no detrimental effect on filter performance from the presence of the strongback. IF\&P's report cover letter stated: "The prototype test results on the $330 \mathrm{~mm}$ candles were very encouraging." This test was also declared a success.

\section{Hot Flow Test Results}

IF\&P originally planned to use their R\&D 161 facility for the hot dust tests. However; during program execution, IF\&P had an opportunity to procure a candle filter hot gas test apparatus from Argonne National Laboratory. This apparatus was assembled at IF\&P's main facility for CFCC strongback reinforced candle filter hot gas testing. As previously mentioned, the target test temperature for hot dust testing was $980^{\circ} \mathrm{C}$. Unfortunately, OSHA regulations and some facility installation oversights reduced the maximum operating temperature of the air preheater and as a result the maximum achievable operating temperature in the filter vessel was only $260^{\circ} \mathrm{C}$. With this limitation, the hot dust tests proceeded.

Two separate 18 hour hot tests were conducted for this effort. The first test used two $330 \mathrm{~mm}$ long traditional (unreinforced) Fibrosic ${ }^{\mathrm{m}}$ filter candles. While the second test used two $330 \mathrm{~mm}$ long, strongback reinforced Fibrosic ${ }^{\mathrm{m}}$ filter candles, strongbacks were from Amercom's lot \#2 delivery. For each test, the filter vessel was charged with 272 grams of calcined MN-23 (simulated coal ash). This amount was calculated to develop a nominal 6-7 $\mathrm{mm}$ dust cake on the two filter candles, based upon their total effective filtration area, the bulk density of the dust and assuming $95-100 \%$ dust fluidization. After introduction of the dust charge, the candle filter test articles were loaded, the filter vessel was sealed and testing commenced. 
Test conditions were as follows:

\begin{tabular}{|r|l|}
\hline Pressure: & Ambient \\
\hline Temperature: & $260^{\circ} \mathrm{C}$ \\
\hline Effective Filtering Area: & 540 square centimeters (per candle) \\
\hline Air Flow: & 7.1 Liters per second \\
\hline Dust Load: & 10,000 to $18,000 \mathrm{ppm}$ \\
\hline Jet Pulse Frequency: & 30 minutes \\
\hline Jet Pulse Pressure: & $620 \mathrm{kPa}$ (gage) \\
\hline Jet Pulse Duration: & 1 second \\
\hline
\end{tabular}

The traditional (unreinforced) candle filters performed the eighteen hour test with a pressure differential of between 140 and 186 inches of water column. This range of $\Delta P$ was significantly higher (almost double) than expected. The cause of this increase in differential pressure was a slight dust leak through the tube sheet. The leak allowed some dust into the clean gas plenum and the cleaning jet pulse drives this dust into the interior wall of the candle filter. Once the dust is embedded in the interior wall of the candle, the operational $\triangle \mathrm{P}$ of the filter is irreversibly increased. Normal filter operation does not dislodge dust that has been embedded in the candle interior by jet pulse force. This dust leak was noted during the test, however, the size of the leak was judged to be small and the test continued. Enough data exists on unreinforced Fibrosic ${ }^{\mathrm{m}}$ candle filters in this test environment that baseline $\Delta \mathrm{P}$ performance was already known. This test was mostly a shake down for the new facility.

The source of the leak was found to be the omission of a Heet-Lok ${ }^{\mathrm{m}}$ gasket at one of the tube sheet penetrations. The gasket was installed and the second test, with strongback reinforced candle filters, was initiated.

Using identical conditions, a $\Delta P$ range of 70 to 112 inches of water column was established for the strongback reinforced candle filters. This range of pressure differential is within the normal range for candle filters under this type of test; the test was considered -. "highly successful." The "Observations and Conclusions" section of IF\&P's test report is copied below, for documentation.

\section{Observations and Conclusions}

Upon disassembly of the filter vessel in each of these tests, no evidence of physical degradation in either case was noted, although from prior experience it is known 
that traditional Fibrosic filter candles can quickly fail, usually immediately after a jet pulse cleaning event.

The higher overall pressure differential observed in the traditional Fibrosic filter candle test series is attributed to the fact that some dust leakage was observed in this test. Some of the dust leaking over to the downstream side of the filter can be driven (irreversibly) into the clean side of the filter candle, which increases pressure differential.

In conclusion, it appears as though the Strongback Fibrosic filter candles can meet or exceed the filtration performance of traditional Fibrosic candles, with a much lower risk of mechanical failure owing to their significantly enhanced strength.

\section{Proposed End-User Service Tests}

IF\&P's relationship with Morgantown Energy Technology Center opened the opportunity to supply the Wilsonville facility with prototypical strongback reinforced candle filters. Wilsonville is a DOE operated demonstration facility with both integrated gasification combined cycle and pressurized fluidized bed combustors. The Wilsonville facility was scheduled for hot gas clean-up trials during the 1996/1997 calendar years', IF\&P was included in the test schedule. Participants would supply entire filter systems that would be installed, as a unit, at the facility. The system would then start up and go through a series of tests. When evaluation was complete, or if the system failed catastrophically, the next filter system would be rotated in. To participate, each company would essentially" "park a filtration system on METC's dock" and await the next test opening. Given this test arrangement, we were able to develop the strongback reinforced Fibrosic ${ }^{\text {mil }}$ filters through simulation tests and enter an end-user service test with high confidence prototypes. There was no rigid test schedule that could force a compromise in development of the reinforced candle filters.

Simulation testing was underway when the program was shutdown. No strongback reinforced candle filters were ever delivered to Wilsonville for testing.

\subsection{Joining}

The objective of this task was to develop the requisite technologies for the attachment of the CFCC composites to the mating hardware for each application. In general, the joining of two different materials must accommodate different thermal expansion rates during temperature changes, while at the same time providing for an adequate transfer of structural, thermal and/or physical loads. Amercom's approach to joining was to address the specific joining issues associated with each CFCC component application rather than initiate generic joining studies and trials at the beginning of the program phase. For this reason, Amercom's joining task did not begin until June of 1995. By this date, we had 
firm designs for both the hot gas filter and the hot gas fan; the piston ring did not require any joining technology. With the delayed task start, and internal cost control issues that created a six month suspension of the program, only twelve months of effort were completed within the joining task.

Amercom's joining effort was broken down into two discrete tasks, composite to composite joining and composite to metal joining. For the $\mathrm{CFCC}$ applications selected by Amercom, there was no requirement to address composite to ceramic joining. A summary of the work performed on these two sub-tasks is provided below.

\subsubsection{Composite to Composite}

To initiate this effort, Amercom attended a Joining Workshop during April of 1995. The workshop participants included representatives from INEL, LBL, Pacific Northwest Laboratory, NOVA and UCB (collectively known as the BES-DMS materials joining project headed by Ames Laboratory) and CFCC contractors. The result of this meeting was a general understanding of each representatives' needs and/or capabilities. Amercom formulated a tentative plan for each of the BES-DMS participants and agreed on specimen size for joining experiments. Amercom was to provide NOI treated CFCC's for joining experiments. This was of keen interest because the NOI chemistry was still evolving and reactivity between the join material, NOI and fiber was a concern. The results of these studies could be used to guide the NOI development toward a joint compatible NOI.

NOI treated CFCC specimens were prepared for delivery to BES team members. One half of the specimens were ground on one surface to expose the fiber/matrix interface to the joining process and media. The other half of the supplied specimens were joined against their as fabricated (SiC) surfaces. BES team members performed the joining and returned the joined specimens to Amercom for test and evaluation. Upon receipt, Amercom sectioned each specimen along its long axis. One half of the sectioned specimen was to be subjected to shear loading to create a fracture in the joint region. This region would undergo SEM observations and an assessment would be made based on those observations regarding the effects of the joining on the CFCC material. The other half of the sectioned specimen were subjected to oxidation heat treatment to evaluate the oxidation performance of the joint, relative to the as fabricated joint. These heat treated specimens were polished and examined to determine the effects of the joining operation on the CFCC material.

\section{AMES}

Cursory SEM evaluation of the lap joints showed good filling of the rough substrate surfaces and no observable attack of the SiC matrix. After 24 hours of air oxidation exposure at $1100^{\circ} \mathrm{C}$, the sample showed some joint/fiber interaction. After 100 hours of air oxidation at $1100^{\circ} \mathrm{C}, \mathrm{SEM}$ observations continued to show minor changes in the 
appearance of the joint region. The structural integrity of the joint appeared to remain intact following the full 100 hour oxidation exposure.

Additional CFCC specimens were delivered to AMES Laboratory for lap joint bonding. This experimental lot consisted of CFCC specimens with ceramic grade Nicalon reinforcement, some with NOI and some using conventional pyrolytic carbon (PyC), along with several specimens that contained Hi Nicalon with the NOI. SEM analysis of the as received samples indicated some degree of degradation within the PyC interfaced specimens. The other specimens, NOI interfaced CG and Hi Nicalon, showed no degradation.

Some of these lap joint specimens were sent to Argonne National Laboratory to establish baseline characteristics for infrared thermographic and air coupled acoustic testing. Unfortunately, these specimens failed during preparation at Argonne. Replacement lap joint specimens were being fabricated when the CFCC program was halted.

Plans were underway to supply CFCC tube material to AMES for additional bonding trials. The tube specimens would be Nicalon reinforced SiC, with the NOI. The tubes were nominally one inch in diameter, two tube segments would make up the eight inch long bond specimen. One tube from each specimen set would be flared at one end to form the "bell" of a bell and spigot joint. These type of joints were of great interest to Amercom because complex shape radiant burner tubes (" $U$ " tube and "W" tube) cannot be fabricated as a single preform with current preforming technology. Successful demonstration of a bell and spigot joining technology would offer a solution to the one piece manufacturing complications. Bonded tube specimens were planned to undergo 100 and 500 hour air oxidation exposure at $1100^{\circ} \mathrm{C}$. Following oxidation exposure, compression shear tests and microscopic evaluations were to be conducted.

Unfortunately, these specimens were in process when the CFCC program was halted; no bell and spigot joints were tested.

\section{NOVA}

Cursory SEM evaluation of the NOVA joint showed good filling of the rough substrate surfaces and no observable attack of the $\mathrm{SiC}$ matrix. After 24 hours of air oxidation exposure at $1100^{\circ} \mathrm{C}$, the sample showed no interaction between the joint region materials. SEM observations of the joint region continued to show no change following the 100 hour air oxidation exposure at $1100^{\circ} \mathrm{C}$. The structural integrity of the joint appeared unaffected by the 100 hour oxidation exposure. 


\subsubsection{Composite to Metal}

\section{Bonding Experiments}

As the result of a meeting with the BES team, an initial plan for composite to metal joining was formulated. Inconnel 718 and NOI treated CFCC were selected as baseline materials. Commercially available Au/Pd and TiCuSiL braze alloys were selected as initial joining materials. The first set of joint specimens would be comprised of ground CFCC specimens bonded to Inco 718 (16 gage) using the Au/Pd compound. A second specimen set would consist of the same base materials, however, a layer of $\mathrm{Ni} / \mathrm{Cr}$ alloy fiber mat would be included in the lap joint to provide strain isolation between the CFCC and the metal. This work was underway when the CFCC program was halted; no joint tests were performed.

\section{Mechanical Attachment}

Materials Sciences Corporation performed a design analysis for a stacking concept to attach three CFCC hot gas fan blade segments to a superalloy shaft. The design is based on the stress free fastener design by Sawyer, Blosser and McWithey at NASA Lewis Research Center. The emerging design was a shaft that terminates in a plate and six, equally spaced studs. Three CFCC hot gas fan segments would be stacked and indexed from these studs to form a six paddle fan. Finite element analysis of this design verified low stress levels in the composite, in spite of large temperature gradients through the stack. This stacked arrangement was adopted as the attachment method for first article testing of the CFCC hot gas fan; hardware was fabricated. A mechanical drawing of the CFCC fan and superalloy shaft stacking concept is shown on the following page. 

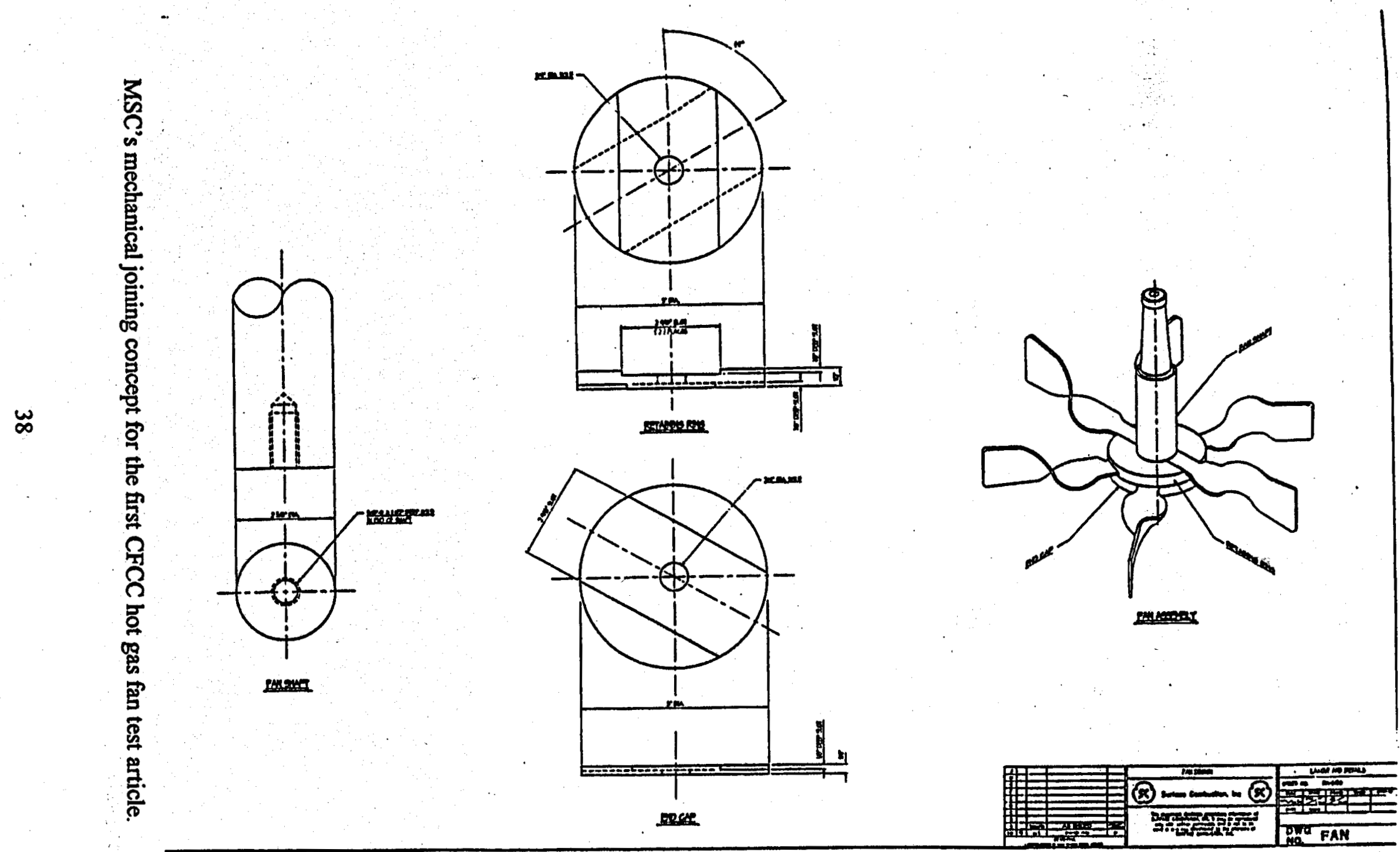


\subsection{Summary, Conclusions and Recommendations}

\subsection{Summary}

Amercom's CFCC program, as far as completed, was a tremendous success. . Critical technologies were developed and refined while commercial CFCC products were produced as demonstration articles. A nonoxidizing interface, the key to CFCC acceptance in commercial markets, was demonstrated. The cold tooling technology was furthered and resulted in the production of CFCC hot gas fan blades. These fan components were produced without conventional CVD tooling. While these technological achievements are important, by far the most significant program achievement was the combination of a CFCC strongback into an already accepted Fibrosic ${ }^{\text {mm }}$ candle filter. The resulting reinforced candle filter easily passed all simulation tests devised by the filter manufacturer (Industrial Filter \& Pump) and was destined for end-user service testing at the DOE demonstration facility in Wilsonville, Alabama. With only one remaining simulation test remaining, full temperature filtration with coal ash at full face velocity, a preform order for the Wilsonville test articles was pending when the program was terminated. Both ARC and IF\&P engineering were confident that simulation testing would conclude with a successful final test. Further, end-user service tests would demonstrate the capability of IF\&P's reinforced candle filters to the power generation community. It is truly unfortunate that end-user service tests were not completed during this program.

As with most development programs, Amercom's CFCC program was not without setbacks. The NOI development was painfully slow. This was due primarily to the cumbersome process and a detailed review of each process step. The development was so slow that during some years only two NOI experiments were completed.

The Detroit Diesel Corporation piston ring development did not go well at all. As development continued, a cascade of technical issues arose; each one complicating the final product and driving up the cost of manufacture. The target selling price of ten dollars per CFCC piston ring was judged unrealistic with current composite technology.

In summary, Amercom's CFCC program successes and technological advancements by far outweigh the few and minor setbacks. This was a successful program which opened several doors for CFCC components within commercial markets. Further, key technical personnel in a variety of industries became aware of CFCCs and their capabilities. 


\subsection{Conclusions}

\section{Nonoxidizing Interface}

An oxidation resistant interface was demonstrated. The as fabricated, room temperature properties of CFCC specimens with this interface were $163 \mathrm{MPa}$ ultimate tensile strength with $0.25 \%$ strain at failure; these properties are roughly $70 \%$ and $40 \%$ (respectively) of typical $\mathrm{SiC} / \mathrm{SiC}$ properties. While these properties are not overly impressive, they are reasonable and designs could be generated based upon them. Post oxidation testing of these NOI interfaced CFCC specimens resulted in an ultimate tensile strength of $106 \mathrm{MPa}$ with a strain at failure of $0.1 \%$. Again, not overly impressive but roughly three times better than typical, PyC interfaced, $\mathrm{SiC} / \mathrm{SiC}$ composite properties after oxidation exposure. The conclusion here is that, while not fully developed, a path to a nonoxidizing interface has been found. Further investigation and development will yield a nonoxidizing interface for ceramic composites and greatly increase the usefulness of CFCCs in the commercial marketplace.

\section{Cold Tooling}

From program inception, it was clear that in order to meet the price requirements of the commercial marketplace, the cost of CFCC manufacturing must be reduced. One of the largest costs associated with the manufacture of complex shaped CFCC components is the tooling cost. Not only are the tools expensive to produce, but they often can be used to produce only one CFCC component. The development of cold tooling technology is critical to successful commercialization of CFCC components.

Amercom's Phase I effort investigated preceramic polymers as cold tooling compounds. Unfortunately, the Phase II effort did not reach the point where the preceramic polymers were used in conjunction with the NOI. Since the NOI was under continuous development, it was never available for component development experiments. There was no benefit to combining the preceramic polymers with the conventional PyC interface. For this reason, all Phase II cold tooling activity was focused on the design and fabrication of cold tools. These tools were designed to be compatible with both the organic and preceramic polymers and would have eventually been used to cold tool NOI interfaced components with the preceramic polymers. However, this stage of development was never reached and all Phase II cold tooling was performed with resin based cold tooling compounds.

\section{CFCC Diesel Piston Rings}

It would seem, from discussions with Detroit Diesel Corporation, that a twenty dollar or less selling price for the CFCC piston ring is essential for commercial acceptance. Our cost projections for CFCC piston ring production were consistently an order of magnitude 
higher than the acceptable price. We concluded that based on these cost issues, the CFCC manufacturing technology was not sufficiently developed to allow penetration of the commercial diesel engine marketplace. Development of the CFCC diesel piston ring was formally halted during July 1996.

\section{CFCC Hot Gas Fans}

The concept for a CFCC hot gas fan was fully developed. CFCC blade segments were produced and a superalloy shaft was fabricated. Amercom and Surface Combustion staffs were approximately two weeks away first article assembly when the when the program was stopped. The last remaining machining operation was the "drilling" of the assembly holes in the hub region of each fan blade segment; this machining operation was never completed.

Testing of the first article hot gas fan would have generated some useful data and probably would have led to a commercially available CFCC hot gas fan. The CFCC fan would have been a furnace option selected at the time of order placement, or perhaps a retrofit option for existing furnaces. While this test was a necessary first step to develop a commercially viable CFCC hot gas fan, it served a second much more important function. These simulation tests were to desensitize Surface Combustion and their customer base to CFCC components. The Midwest heat treatment community is very conservative and was not expected to readily embrace a new, and expensive, component in their workhorse furnaces. The CFCC hot gas fan was an introductory product for this industry. The fan, by itself, is maybe a one-half million dollar per year market when fully developed. The real market in the heat treatment industry are the remaining furnace components. These include trays, rollers, rails and radiant bumer tubes. The potential market for radiant burner tubes is ten of millions of dollars per year. The hot gas fan was just the first step toward capturing these markets and we almost took this first step. This product and these markets are worth pursuing.

\section{CFCC Hot Gas Filters}

The success in simulation test of the strongback reinforced Fibrosic ${ }^{\text {tm }}$ candle filters generated considerable interest throughout the user community. IF\&P kept their METC contacts briefed as the testing progressed. When the program began, only Amercom had identified hot gas filters as a CFCC application. However, by late 1997 several other CFCC participants had included hot gas filters within their program scope. The reason that so many companies are interested in hot gas filtration is the large and lucrative potential market. Sales projections run into the tens of millions of dollars per year and the first company to achieve success will certainly gain a large market share. The Amercom

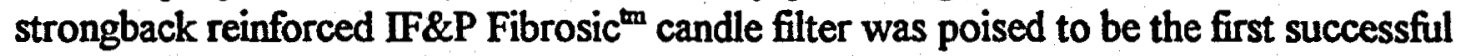
demonstration of a durable, long life hot gas filter. 
Hot gas filtration is an critical technology to the success of PFBC and IGCC power cycles; both of which were developed by the DOE. It is essential that this work be continued and a successful hot gas filter demonstrated.

\subsection{Recommendations}

\section{Nonoxidizing Interface}

Continued funding of NOI development is highly recommended. The current state of development indicates that a NOI is feasible and near. In order to penetrate the target markets, a NOI essential. Depending on the outcome of technology ownership, given the closure of Amercom, interested parties should be briefed on Amercom's NOI development and funded to continue the development. This technology was the comerstone of the Amercom's CFCC program and absolutely essential to achievement of the program goals. We offer this as the highest priority recommendation.

\section{Cold Tooling}

Amercom has developed production scale cold tooling technology and developed both organic and preceramic polymers to use as rigidizing compounds. The organic route has been fully demonstrated and only the preceramic polymer demonstration remains. Some additional development funding will be required to complete the demonstration of preceramic cold tooling. However, no further development of cold tooling is warranted until the NOI has reached a higher level of development.

\section{CFCC Diesel Piston Rings}

Given the current state of CFCC manufacturing technology and the cost driven environment of the "automotive" industry, the time is not right for introduction of CFCC components. As manufacturing technology improves and EPA regulations tighten, the ability to penetrate this market will also improve.

At this time we recommend no further development of CFCC diesel piston rings. However, an open dialogue between the engine manufactures and CFCC suppliers should continue.

\section{CFCC Hot Gas Fans}

The development of a hot gas fan was Amercom's entrée into the commercial heat treatment industry. Most of the other CFCC teams, who selected this arena, choose radiant burner tubes as their target component. Radiant burner tubes are a much more complex component and introduce issues of joining and through the wall permeability. Amercom chose the hot gas fans as a straight forward, relatively easy introductory 
component to gain the acceptance of the user community. We understood that as a single component, the hot gas fan was not a viable stand alone business opportunity. If others wish to continue the hot gas fan development, again depending upon the outcome of technology ownership, they should receive Amercom's hot gas fan development data and be funded to continue development.

\section{CFCC Hot Gas Filters}

The strongback reinforced Fibrosic ${ }^{\text {min }}$ candle filters were clearly the most significant application within Amercom's CFCC program. The technology worked, the market existed and there were no other competitors with a better product. We strongly recommend that this technology be continued. The DOE should actively seek CFCC suppliers to continue the strongback development and prototype production. IF\&P is an outstanding OEM to market this product. This should be taken as our second highest program recommendation. 